\title{
Juvenile Administration of Concomitant Methylphenidate and Fluoxetine Alters Behavioral Reactivity to Reward- and Mood-Related Stimuli and Disrupts Ventral Tegmental Area Gene Expression in Adulthood
}

\author{
Brandon L. Warren, ${ }^{1 \star}$ Sergio D. Iñiguez, ${ }^{1,2 *}$ Lyonna F. Alcantara, ${ }^{1}$ Katherine N. Wright, ${ }^{1}$ Eric M. Parise, ${ }^{1}$ \\ Sarah K. Weakley, ${ }^{1}$ and Carlos A. Bolaños-Guzmán ${ }^{1}$ \\ ${ }^{1}$ Department of Psychology and Program in Neuroscience, Florida State University, Tallahassee, Florida 32306, and ${ }^{2}$ Department of Psychology, California \\ State University, San Bernardino, California 92407
}

There is a rise in the concurrent use of methylphenidate (MPH) and fluoxetine (FLX) in pediatric populations. However, the long-term neurobiological consequences of combined MPH and FLX treatment (MPH + FLX) during juvenile periods are unknown. We administered saline (VEH), MPH, FLX, or MPH + FLX to juvenile Sprague Dawley male rats from postnatal day 20 to 34, and assessed their reactivity to reward- and mood-related stimuli $24 \mathrm{~h}$ or 2 months after drug exposure. We also assessed mRNA and protein levels within the ventral tegmental area (VTA) to determine the effect of MPH, FLX, or MPH + FLX on the extracellular signal-regulated protein kinase-1/2 (ERK) pathway-a signaling cascade implicated in motivation and mood regulation. MPH + FLX enhanced sensitivity to drug (i.e., cocaine) and sucrose rewards, as well as anxiety (i.e., elevated plus maze)- and stress (i.e., forced swimming)-eliciting situations when compared with VEH-treated rats. MPH + FLX exposure also increased mRNA of ERK2 and its downstream targets cAMP response element-binding protein (CREB), BDNF, c-Fos, early growth response protein-1 (Zif268), and mammalian target of rapamycin (mTOR), and also increased protein phosphorylation of ERK2, CREB, and mTOR 2 months after drug exposure when compared with VEH-treated rats. Using herpes simplex virus-mediated gene transfer to block ERK2 activity within the VTA, we rescued the MPH and FLX-induced behavioral deficits seen in the forced-swimming task 2 months after drug treatment. These results indicate that concurrent MPH + FLX exposure during preadolescence increases sensitivity to reward-related stimuli while simultaneously enhancing susceptibility to stressful situations, at least in part, due to long-lasting disruptions in ERK signaling within the VTA.

\section{Introduction}

Attention deficit/hyperactivity disorder (ADHD) and major depressive disorder (MDD) often co-occur with up to $40 \%$ prevalence in pediatric populations (Waxmonsky, 2003; Spencer, 2006). The stimulant methylphenidate (MPH) (Ritalin), an effective agent for the management of ADHD (Castle et al., 2007), and the antidepressant fluoxetine (FLX) (Prozac), the only drug approved for treatment of pediatric MDD (Safer, 2006), are therapeutic agents often combined (MPH + FLX) as a treatment

\footnotetext{
Received March 23, 2011; revised May 17, 2011; accepted May 20, 2011.

Author contributions: C.A.B.-G. designed research; B.L.W., S.D.I., L.F.A., K.N.W., E.M.P., and S.K.W. performed research; B.L.W., S.D.I., E.M.P., and C.A.B.-G. analyzed data; B.L.W., S.D.I., and C.A.B.-G. wrote the paper.

This work was supported by National Institute on Drug Abuse (NIDA) Grants R21DA022351-01 and R011DA026854-01. B.L.W. was supported by a Neuroscience Fellowship from Florida State University. S.D.I. was supported by a McKnight Fellowship from the Florida Education Fund, a Neuroscience Fellowship from Florida State University, and NIDA National Research Service Award F31DA027300. We are grateful to Dr. Eric J. Nestler for generously providing the viral vectors used in these studies, to Dr. Vaishnav Krishnan for insightful discussions on earlier versions of the manuscript, and to Raul J. Arispe for editorial assistance.

${ }^{*}$ B.L.W. and S.D.I. contributed equally to this work.

Correspondence should be addressed to Dr. Carlos A. Bolaños-Guzmán, Department of Psychology, Florida State University, 1107 West Call Street, Tallahassee, FL 32306. E-mail: bolanos@psy.fsu.edu.

DOI:10.1523/JNEUROSCI.1470-11.2011

Copyright $\odot 2011$ the authors $\quad 0270-6474 / 11 / 3110347-12 \$ 15.00 / 0$
}

strategy for comorbid ADHD and MDD during early life (Rushton and Whitmire, 2001; Safer et al., 2003). Nevertheless, concerns regarding the safety and adverse effects associated with concomitant drug use in youths have emerged (Zito et al., 2008).

Despite prevalent MPH and FLX use, the neurobiological consequences of their combined use during juvenile periods are unknown (Bhatara et al., 2004; Spencer, 2006). This is particularly striking because together these drugs may have pharmacodynamic properties similar to cocaine. MPH and cocaine act through inhibition of dopamine transporters (Volkow et al., 2002), and the mechanistic differences between these drugs may be partly due to inhibition of serotonin transporters by cocaine, since MPH has a much lower affinity for the serotonin transporter (Han and Gu, 2006; Yano and Steiner, 2007). Thus, the concurrent use of MPH with the serotonin transporter blocker, FLX, may induce emergent effects similar to those of cocaine by simultaneously inhibiting the reuptake of both serotonin and dopamine. Accordingly, an acute dose of MPH + FLX robustly induces immediate early gene transcription and behavioral reactivity in adult rats, as cocaine does (Steiner et al., 2010).

The long-term consequences of juvenile exposure to MPH or FLX have only recently begun to be elucidated. MPH exposure in 
juvenile rats increases sensitivity to stress- and anxiety-eliciting situations while decreasing sensitivity to both natural and drug rewards in adulthood (Andersen et al., 2002; Bolaños et al., 2003b). Conversely, FLX treatment during adolescence increases sensitivity to anxiety-eliciting circumstances and to natural rewards, but decreases sensitivity to stress in adulthood (Karpova et al., 2009; Iñiguez et al., 2010a). The mechanisms underlying these long-lasting effects are unknown. However, signaling molecules linked to neurotrophic factors are increasingly implicated in the neural adaptations accompanying stress, psychostimulant, and antidepressant drug exposure (Bolaños and Nestler, 2004; Duman, 2004). Specifically, the downstream target of brain-derived neurotrophic factor (BDNF), extracellular signal-regulated protein kinase-1/2 (ERK), and its targets cAMP response element-binding protein (CREB), mammalian target of rapamycin (mTOR), and the immediate early gene Zif268 have been implicated in these cellular processes (Mutschler et al., 2000; Carlezon et al., 2005; Covington et al., 2005; Fumagalli et al., 2005; Lu et al., 2006; Iñiguez et al., 2010c; Subramaniam and Unsicker, 2010). Therefore, the major goal of this investigation was to assess the effect of juvenile MPH + FLX treatment on functional responsiveness to rewards, mood-related stimuli, and the expression of ERK-related molecules within the ventral tegmental area (VTA), a neural substrate implicated in the regulation of mood (Bolaños et al., 2003a; Eisch et al., 2003; Nestler and Carlezon, 2006; Iñiguez et al., 2010b).

\section{Materials and Methods}

Animals. Litters containing Sprague Dawley male rat pups with their dams [postnatal day 14 (PD14) on arrival] (Charles River Laboratories) were used in this study. Rats were housed in clear polypropylene boxes containing wood shavings in an animal colony maintained at $23-25^{\circ} \mathrm{C}$ on a $12 \mathrm{~h} \mathrm{light/dark} \mathrm{cycle} \mathrm{in} \mathrm{which} \mathrm{lights} \mathrm{were} \mathrm{on} \mathrm{between}$ 7:00 A.M. and 7:00 P.M. Food and water were provided ad libitum. All procedures were in strict accordance with the Guidelines for the Care and Use of Mammals in Neuroscience and Behavioral Research (National Research Council, 2003) and approved by the Florida State University Animal Care and Use Committee.

Drug treatment and experimental design. MPH (methylphenidate hydrochloride), FLX (fluoxetine hydrochloride), and cocaine hydrochloride were obtained from Sigma-Aldrich. Each drug was dissolved in $0.9 \%$ sterile saline $(\mathrm{VEH})$ and administered in a volume of $1 \mathrm{ml} / \mathrm{kg}$ for MPH and cocaine, and $2 \mathrm{ml} / \mathrm{kg}$ for FLX and MPH + FLX. Intraperitoneal injections of MPH (2.0 mg/kg), FLX (2.5 mg/kg), MPH + FLX (2.0 and $2.5 \mathrm{mg} / \mathrm{kg}$, respectively), or VEH were given to pups starting at PD20 twice daily ( $4 \mathrm{~h}$ apart) for $15 \mathrm{~d}$ (PD20-PD34). The dose of each drug was selected based on previous reports that have validated these dosing regimens to expected behavioral outcomes and approximate clinically relevant dosing in humans (Wargin et al., 1983; Andersen et al., 2002; Bolaños et al., 2003b; Carlezon et al., 2003; Brenhouse et al., 2009; Steiner et al., 2010). From PD20 to PD23, VEH-, MPH-, FLX-, and MPH + FLX-treated rats were kept together in the same cage with their dams. At PD24 (weaning), rats were separated by treatment condition into groups of four per cage. At PD45, rats assigned to the long-term testing condition were further separated into groups of two per cage and were left undisturbed until adulthood (PD94). Rats assigned to the short-term behavioral testing condition were tested on PD35, while those assigned to the long-term behavioral testing condition were tested in adulthood (PD94) (Fig. 1). The period between PD20 and PD34 was chosen because it approximates preadolescence (i.e., 4-12 years of age) in humans (Spear, 2000; Andersen and Navalta, 2004). All behaviors, except for the place conditioning and sucrose preference tasks, were recorded with a video camera located on the ceiling of separate testing rooms. Rats were exposed to no more than two behavioral tasks. For specific testing sequence, see Table 1. Behavioral observations and analyses were performed by observers blind to the treatment conditions of each subject.

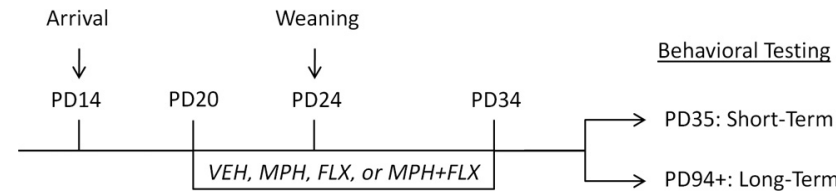

Figure 1. Timeline of developmental drug treatment and experimental procedures. Rats arrived in the laboratory with their dams at PD14. Rats were randomly assigned to receive VEH, MPH $(2.0 \mathrm{mg} / \mathrm{kg}), F L X(2.5 \mathrm{mg} / \mathrm{kg})$, or MPH + FLX (2.0 and $2.5 \mathrm{mg} / \mathrm{kg}$, respectively) from PD20 until PD34 twice daily, $4 \mathrm{~h}$ apart (9:00 A.M. and 1:00 P.M.). Rats were weaned at PD24 and tested either $24 \mathrm{~h}$ after the last injection (PD35; short term) or 2 months later, when they reached adulthood (PD94; long term).

Place conditioning. Place conditioning for cocaine was performed in a three-compartment apparatus as described previously (Andersen et al., 2002; Bolaños et al., 2008; Iñiguez et al., 2008). Compartments differed in floor texture, wall coloring, and lighting. On the preconditioning day (day 0 ), rats were allowed to explore the entire apparatus for $30 \mathrm{~min}$ to obtain baseline preference to any of the three compartments (length by width by height: side compartments, $35 \times 27 \times 25 \mathrm{~cm}$; middle compartment, $10 \times 27 \times 25 \mathrm{~cm}$ ). Only rats showing no preference (before cocaine exposure) to either side compartment were used; this accounted for $>90 \%$ of all of the rats tested. Conditioning trials occurred over 2 consecutive days. During conditioning, rats received saline $(1 \mathrm{ml} / \mathrm{kg}$, i.p.) and were confined to one of the side compartments of the apparatus for $30 \mathrm{~min}$. After $3 \mathrm{~h}$, rats received cocaine (0, 5, or $10 \mathrm{mg} / \mathrm{kg}$, i.p.) and were confined to the opposite side compartment (drug-paired compartment) for $30 \mathrm{~min}$. On the test day (day 3 ), rats received saline and were allowed to explore the entire apparatus for $20 \mathrm{~min}$ and time spent in the drugpaired compartment was assessed (drug side minus saline side).

Sucrose preference. The sucrose preference test consisted of a twobottle choice procedure in which rats were given the choice between consuming water and a sucrose solution. This paradigm has been used extensively to assess the effects of stress-induced anhedonia (Willner et al., 1987). Rats were habituated to drink water from two bottles for $5 \mathrm{~d}$. At the start of the experiment, they were exposed to ascending concentrations of sucrose $(0,0.125,0.25,0.5$, and $1 \%)$ for $2 \mathrm{~d}$ per sucrose concentration (Wallace et al., 2008). Water and sucrose consumption was measured at 8:00 A.M. and 5:00 P.M. each testing day. The position of the sucrose bottle (left or right) was counterbalanced between groups and changed daily. Preference for sucrose over water [sucrose/(sucrose + water)] was used as a measure for rats' sensitivity to reward.

Elevated plus maze. VEH-, MPH-, FLX-, and MPH + FLX-pretreated rats were tested on the elevated plus maze, a behavioral task assessing anxiety-like behavior (Montgomery and Monkman, 1955). The maze consisted of two perpendicular, intersecting runways $(12 \mathrm{~cm}$ wide $\times 100 \mathrm{~cm}$ long) made from gray plastic. One runway had tall walls $(40 \mathrm{~cm}$ high), termed "closed arms," while the other had no walls, termed "open arms." The arms were connected together by a central area, and the maze was elevated $1 \mathrm{~m}$ from the floor. Testing was conducted between 9:00 A.M. and 1:00 P.M. under controlled light conditions ( $\sim 90$ lux) as described previously (Bolaños et al., 2003b; Iñiguez et al., 2009). At the start of the test, rats were positioned in the central area, facing one of the open arms and allowed to explore freely for $5 \mathrm{~min}$, and the percentage time that the rat's center point (as determined by Noldus Ethovision XT) spent in the open versus closed arms was measured [100 $\times$ (total time spent in open arms/total time spent in closed arms)].

Forced swimming. The forced-swim test is a $2 \mathrm{~d}$ procedure in which rats are forced to swim under inescapable conditions (Porsolt et al., 1977). On day 1, rats are forced to swim for $15 \mathrm{~min}$. Initially, they engage in escape-like behaviors but eventually adopt a posture of immobility in which they make only the movements necessary to maintain their head above water. When retested $24 \mathrm{~h}$ later, rats become immobile very quickly; however, antidepressant treatment between the forced-swim exposures can significantly increase their escape-like behaviors, an effect that has been correlated with antidepressant activity in humans (Cryan et al., 2002). At the start of the experiment, rats were placed in plastic cylinders $(75 \times 30 \mathrm{~cm})$ filled to $54 \mathrm{~cm}$ depth with $25^{\circ} \mathrm{C}$ water, as described previ- 
Table 1. Experimental groups and testing sequence

\begin{tabular}{|c|c|c|c|c|c|c|}
\hline Group & $N$ & Treatment & Interval 1 & Test 1 & Interval 2 & Test 2 \\
\hline 1 & 78 & VEH, MPH, FLX, or MPH + FLX & $24 \mathrm{~h}$ & Conditioned place preference & $X$ & $x$ \\
\hline 2 & 30 & VEH, MPH, FLX, or MPH + FLX & $24 \mathrm{~h}$ & Elevated plus maze & 2 months & Forced-swim test \\
\hline 3 & 30 & VEH, MPH, FLX, or MPH + FLX & $24 \mathrm{~h}$ & Forced swim test & $x$ & $X$ \\
\hline 4 & 32 & VEH, MPH, FLX, or MPH + FLX & $24 \mathrm{~h}$ & $q P C R$ & $X$ & $X$ \\
\hline 5 & 77 & VEH, MPH, FLX, or MPH + FLX & 2 months & Conditioned place preference & $X$ & $X$ \\
\hline 6 & 40 & VEH, MPH, FLX, or MPH + FLX & 2 months & Sucrose preference & $48 \mathrm{~h}$ & Elevated plus maze \\
\hline 7 & 32 & VEH, MPH, FLX, or MPH + FLX & 2 months & qPCR or Western blot & $X$ & $x$ \\
\hline 8 & 47 & VEH, MPH, FLX, or MPH + FLX & 2 months & Viral surgery & $3 d$ & Forced-swim test \\
\hline
\end{tabular}

VEH, $0.9 \%$ sterile saline; MPH, methylphenidate (2.0 mg/kg); FLX, fluoxetine $(2.5 \mathrm{mg} / \mathrm{kg}) ; \mathrm{MPH}+\mathrm{FLX}$, methylphenidate and fluoxetine (2.0 and $2.5 \mathrm{mg} / \mathrm{kg}$, respectively); qPCR, quantitative real-time reverse transcription-PCR.

Table 2. qPCR primers

\begin{tabular}{|c|c|c|}
\hline \multirow[b]{2}{*}{ Gene } & \multicolumn{2}{|l|}{ Primer sequence } \\
\hline & Forward & Reverse \\
\hline ERK2 & $5^{\prime}$-CACAGCACCTCAGCAATGAT-3' & $5^{\prime}$-GTTCAGCAGGAGGTTGGAAG-3' \\
\hline CREB & $5^{\prime}$-GGCCTGCAGACATTAACCAT-3' & 5'-TCCATCAGTGGTCTGTGCAT-3' \\
\hline BDNF & $5^{\prime}$-GGTCACAGTCCTGGAGAAAG-3' & 5'-GTCTATCCTTATGAACCGCC-3' \\
\hline c-Fos & $5^{\prime}-\mathrm{GAAGGAACCAGACAGGTCCA-3^{ \prime }}$ & 5'-TCACCCTGCCTCTTCTCAAT-3' \\
\hline Zif268 & $5^{\prime}$-TCTGAATAACGAGAAGGCCGTGGT-3' & $5^{\prime}$-ACAAGGCCACTGACTAGGCTGAAA-3' \\
\hline mTOR & 5'-TTGAGGTTGCTATGACCAGAGAGAA-3' & $5^{\prime}$-TTACCAGAAAGGACACCAGCCAATG-3' \\
\hline GAPDH & 5'-AGGTCGGTGTGAACGGATTTG-3' & 5'-TGTAGACCATGTAGTTGAGGTCA-3' \\
\hline
\end{tabular}

ously (Iñiguez et al., 2009). Afterward, rats were removed from the water, dried with towels, and placed in a warmed enclosure for $30 \mathrm{~min}$. All cylinders were emptied and rinsed between rats. On day 2 ( $24 \mathrm{~h}$ later), rats were retested for 5 min under identical conditions. Here, the latency to become immobile, total immobility, and swimming, climbing, and immobility counts were measured. Behavioral counts were taken at $5 \mathrm{~s}$ intervals during the $5 \mathrm{~min}$ retest. Latency to immobility was defined as the time at which the rat first initiated a stationary posture that did not reflect attempts to escape from the water (Lucki, 1997). To qualify as immobility, this posture had to be clearly visible and maintained for $\geq 2.0$ s (Detke and Lucki, 1996; Carlezon et al., 2003).

Basal locomotor activity after day 1 of forced swimming. Spontaneous locomotor activity was indexed as distance traveled (in centimeters) in an automated open field $(63 \times 63 \mathrm{~cm})$ that consisted of a square box that rats can explore freely (Wiley et al., 2009; Iñiguez et al., 2010a). This behavioral task was performed $24 \mathrm{~h}$ after the forced-swim test on day 1 , to assess whether the effects observed in the forced-swim test (day 2) could be confounded by changes in general locomotor activity after drug pretreatment or viral surgery.

Quantitative real-time reverse transcription-PCR. Rats were killed either $24 \mathrm{~h}$ or 2 months after the last injection of VEH, MPH, FLX, or $\mathrm{MPH}+$ FLX. Punches were taken from VTA (1.25 mm diameter) and stored at $-80^{\circ} \mathrm{C}$ until use. RNA was isolated using RNEasy Micro kits (QIAGEN) and cDNA was created from these samples using iScript cDNA synthesis kit (Bio-Rad). Quantitative real-time reverse transcription-PCRs (qPCRs) were performed in triplicate using 96well PCR plates and RealMasterMix (Eppendorf) with an Eppendorf MasterCycler Realplex ${ }^{2}$ according to manufacturer's instructions. Threshold cycle $[C(t)]$ values were measured using the supplied software and analyzed with the $\Delta \Delta C(t)$ method as described previously (LaPlant et al., 2010; Vialou et al., 2010). Primer sequences for ERK2, CREB, BDNF, c-Fos, Zif268, mTOR, and glyceraldehyde-3-phosphate dehydrogenase (GAPDH) are listed in Table 2.

Western blotting. Tissue punches of VTA (1.25 mm diameter) from rats were sonicated in a standard lysis buffer and then centrifuged at $14,000 \mathrm{rpm}$ for $15 \mathrm{~min}$. Samples (20 $\mu$ g; estimated through Bradford assay) were treated with $\beta$-mercaptoethanol and subsequently electrophoresed on precast 4-20\% gradient gels (Bio-Rad), as previously described (Iñiguez et al., 2011). Proteins were transferred to a polyvinylidene fluoride membrane, washed in $1 \times$ Tris-buffered saline with $0.1 \%$ Tween 20 (TBST), and blocked in milk dissolved in TBST $(5 \% \mathrm{w} / \mathrm{v})$ for $1 \mathrm{~h}$ at $25^{\circ} \mathrm{C}$. Blots were probed (overnight at $4^{\circ} \mathrm{C}$ ) with antibodies against the phosphorylated forms of ERK2, CREB, and mTOR, stripped with Restore (Pierce Bio- technology), and reprobed with antibodies against total CREB, ERK2, mTOR, and GAPDH. All antibodies were from Cell Signaling and were used according to the manufacturer's instructions in 5\% milk dissolved in TBST. After further washes, membranes were incubated with peroxidase-labeled goat anti-rabbit IgG or horse anti-mouse IgG (1: 40,000; Vector Laboratories). Bands were visualized with SuperSignal West Dura substrate (Pierce Biotechnology), quantified using NIH ImageJ, and normalized to GAPDH.

Viral vectors and reversal experiment. Based on the results from the behavioral experiments described above, separate groups of juvenile male rats were treated with VEH or MPH + FLX from PD20-PD34. Two months after the end of drug treatment (PD94), they were microinjected with herpes simplex virus (HSV) vectors encoding green fluorescent protein (GFP) or a dominant-negative mutant of ERK2-GFP (dnERK2) within the VTA to assess whether blockade of ERK2 itself would rescue the MPH + FLX-induced behavioral deficits as measured in the forcedswim test. The construction of the HSV vectors has been described previously (Robinson et al., 1996; Neve et al., 1997), and the HSV-GFP and the HSV-dnERK2 vectors have been validated in vivo and in vitro (Krishnan et al., 2007; Russo et al., 2007; Iñiguez et al., 2010b). The average titer of the recombinant virus stocks was $4.0 \times 10^{7}$ infectious units $/ \mathrm{ml}$. Titers did not differ by $>10 \%$ among preparations. The behavioral experiment was commenced on day 3 after viral surgery (PD97), a time at which maximal transgene expression caused by these vectors is observed (Carlezon et al., 1998; Barrot et al., 2002). As previously reported, expression of the HSV-encoded transgenes was limited to an area of $\sim 1 \mathrm{~mm}^{3}$ around the injection site, and viral expression was not apparent in either afferent or efferent regions of the injected area (Bolaños et al., 2003a; Iñiguez et al., 2008; Krishnan et al., 2008).

Animal surgery. For stereotaxic delivery of the viruses, rats were anesthetized with a ketamine/xylazine mixture $(80 / 10 \mathrm{mg} / \mathrm{kg}, \mathrm{i} . \mathrm{m}$. $)$ and given atropine $(0.25 \mathrm{mg} / \mathrm{kg})$ subcutaneously to minimize bronchial secretions; afterward, rats were given bilateral microinjections $(1.0 \mu \mathrm{l}$ per side over 10 min of either HSV-GFP or -dnERK2) into the rostral region of the VTA [anteroposterior, $-4.9 \mathrm{~mm}$; lateral, $+2.2 \mathrm{~mm}$; dorsoventral, -7.6 mm below dura (Paxinos and Watson, 1997)] using a 32 gauge Hamilton syringe angled at $10^{\circ}$ from the midline, to avoid piercing the sinus system. The local anesthetic bupivacaine was applied directly along the wound edges to minimize any potential postoperative discomfort. The VTA injection sites were confirmed in all rats by standard histology methods (described below).

Histology and transgene detection. At the end of the forced-swim test, rats were given an overdose of pentobarbital and perfused transcardially with $0.9 \%$ saline, followed by cold $4 \%$ paraformaldehyde. The brains were removed, postfixed overnight in $4 \%$ paraformaldehyde, and stored in $20 \%$ glycerol. Coronal sections $(45 \mu \mathrm{m})$ through the midbrain were taken on a microtome and stored in $0.1 \mathrm{M}$ sodium phosphate buffer with $0.05 \%$ azide. Sections were processed to examine the ability of HSV construct to drive expression of GFP and tyrosine hydroxylase (TH) within the VTA as previously described (Russo et al., 2007; Iñiguez et al., 2010b). Midbrain free-floating coronal sections were processed for immunohistochemistry using the following antibodies: rabbit anti-GFP (1: 1000; Abcam), and anti-TH (mouse; 1:5000; Millipore Bioscience Research Reagents), a marker of VTA dopamine neurons. Adjacent sections were blocked in 3\% normal donkey serum (NDS) and incubated overnight in one of the primary antibodies mentioned above, along with 


\section{Cocaine Place Conditioning}
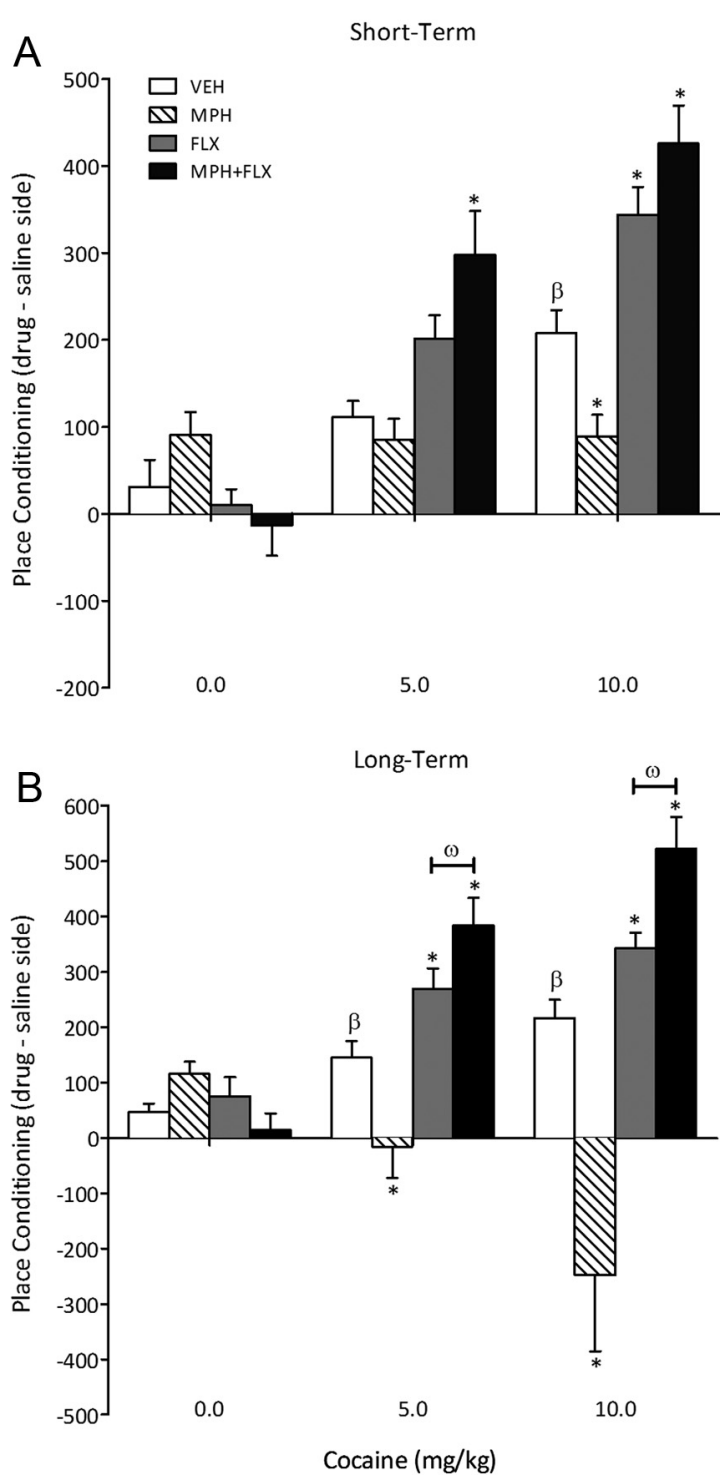

Figure 2. Effects of juvenile exposure to VEH, MPH, FLX, or MPH + FLX on cocaine-induced place conditioning. $\boldsymbol{A}$, Short term (24 $\mathrm{h}$ after the last injection): MPH blunted, whereas FLX increased preference for environments previously paired with cocaine $(10 \mathrm{mg} / \mathrm{kg}) . \mathrm{MPH}+\mathrm{FLX}$ increased preference for the cocaine-paired compartment at 5 and $10 \mathrm{mg} / \mathrm{kg}$ doses when compared with the VEHpretreated controls $(n=5-9$ per group; $p<0.05$, respectively). $\boldsymbol{B}$, Long term ( 2 months after the last injection): $\mathrm{MPH}$-pretreated rats showed a significant aversion to the cocaine-paired compartments, regardless of dose, whereas FLX and MPH + FLX pretreatment increased preference for the cocainepaired compartments ( 5 and $10 \mathrm{mg} / \mathrm{kg}$ ) when compared with VEH-pretreated controls $(n=5-8$ per group; $p<0.05$, respectively). *Significantly different from the VEH-pretreated controls at same dose, $p<0.05$. ${ }^{\beta}$ Significantly different $(p<0.05$ ) from rats conditioned to saline (i.e., $0 \mathrm{mg} / \mathrm{kg}$ cocaine dose). ${ }^{\omega}$ Significantly differentfrom theFLX-pretreated rats at same dose $(p<0.05)$. Data are presented as time spent in the cocaine-paired compartment (drug minus saline side) on test day (mean \pm SEM).

0.3\% Triton X-100 (Thermo Fisher Scientific) and 1\% NDS. Sections were incubated with anti-rabbit or -mouse secondary antibody (Jackson ImmunoResearch) for $2 \mathrm{~h}$ at room temperature. Stained sections were then slide mounted (Thermo Fisher Scientific), dehydrated in ethanol and Citrosolv, and coverslipped with clear DPX adhesive (SigmaAldrich). Slides were then visualized and photographed using a fluorescence microscope and a digital camera. Data obtained from rats with placements outside the intended brain regions $(<10 \%$ of all experimental animals) were not included in the analyses.

\section{Sucrose Preference}
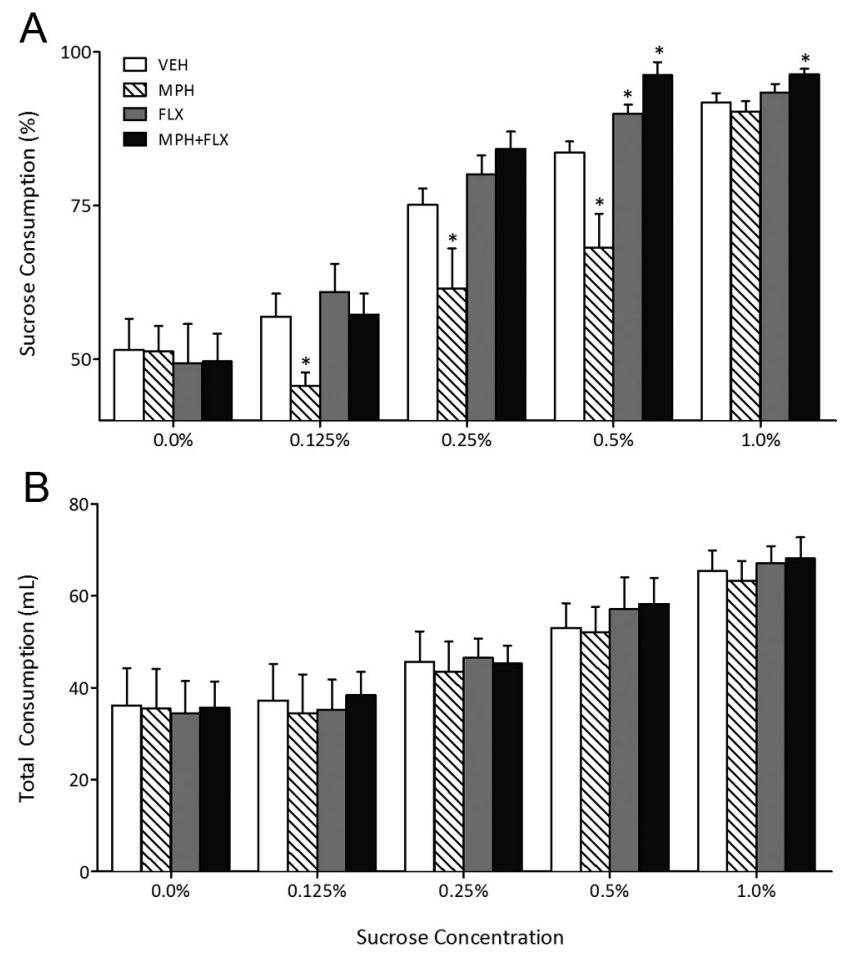

Figure 3. Effects of juvenile exposure to VEH, MPH, FLX, or MPH + FLX on sucrose preference 2 months after the last injection ( $n=9-11$ per group). $A$, Exposure to MPH decreased $p<$ 0.05 ), while FLX and MPH $+F L X$ increased $(p<0.05)$ preference for the sucrose solution when compared with the VEH-pretreated controls. $\boldsymbol{B}$, No differences in total fluid intake (sucrose + water) were detected regardless of treatment. ${ }^{*}$ Significantly different from the VEH-pretreated controls $(p<0.05)$. Data are presented as percentage preference or total milliliters consumed between the treatment groups (mean \pm SEM).

Statistical analyses. Data analysis was assessed using mixed-design (between and within variables) ANOVA followed by least significant difference post hoc tests. When appropriate, Student's $t$ tests were used to determine statistical significance of preplanned comparisons. Data are expressed as the mean \pm SEM. Statistical significance was defined as $p<0.05$.

\section{Results}

Effects of juvenile MPH, FLX, and MPH + FLX exposure on reward-related stimuli

Place conditioning

Sensitivity to cocaine was assessed $24 \mathrm{~h}$ (short term; $N=78$ ) or 2 months (long term; $N=77$ ) following juvenile exposure to $\mathrm{VEH}$, MPH, FLX, or MPH + FLX (Fig. 2). No conditioning effects were detected in rats conditioned with saline $24 \mathrm{~h}$ after chronic drug treatment (Fig. 2A). Time spent in the cocaine-paired compartments varied as a function of drug pretreatment $\left(F_{(3,66)}=11 ; p<\right.$ $0.01)$, cocaine dose $\left(F_{(2,66)}=44.5 ; p<0.01\right)$, and the interaction between the two independent variables $\left(F_{(6,66)}=7.4 ; p<0.01\right)$. VEH-pretreated rats spent significantly more time in the 10 $\mathrm{mg} / \mathrm{kg}$ cocaine-paired compartment when compared with the lower doses $(0$ and $5 \mathrm{mg} / \mathrm{kg})$ of cocaine $(p<0.05 ; n=6-7$ per group). Conversely, MPH-pretreated rats did not develop preference for any of the cocaine-paired compartments when compared with the VEH-pretreated controls $(p>0.05 ; n=5-7$ per group). FLX-pretreated rats spent significantly more time in the $10 \mathrm{mg} / \mathrm{kg}$ cocaine-paired compartment $(p<0.05 ; n=5-8$ per group), whereas rats in the MPH + FLX pretreatment condition showed increased place preference at both the 5 and $10 \mathrm{mg} / \mathrm{kg}$ 


\section{Elevated Plus Maze}

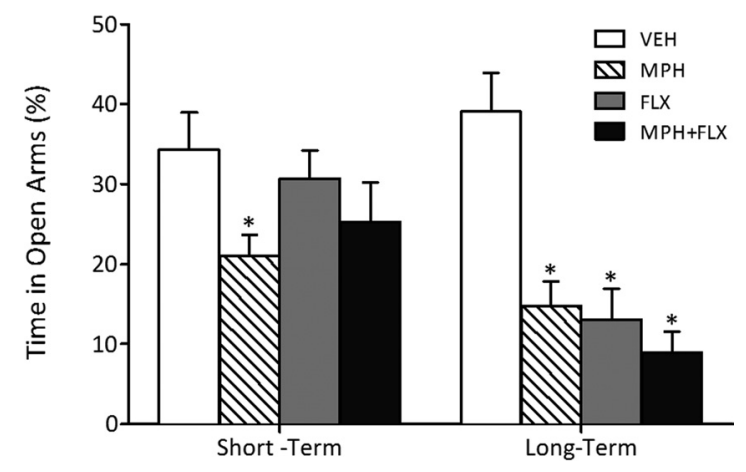

Figure 4. Effects of juvenile exposure to VEH, MPH, FLX, or MPH + FLX on anxiety-like behavior in the elevated plus maze. Short term ( $24 \mathrm{~h}$ after the last injection; $n=7-8$ per group): Only MPH-pretreated rats spent significantly $(p<0.05)$ less time in the open arms when compared with the VEH-pretreated controls (left panel). Long term (2 months after the last injection; $n=8-12$ per group): MPH, FLX, and MPH + FLX decreased time spent in the open arms when compared with the VEH-pretreated controls ( $p<0.05$; right panel). * Significantly different from the VEH-pretreated controls. Data are presented as percentage time (mean \pm SEM). cocaine doses when compared with the VEH-pretreated controls ( $p<0.05 ; n=5-9$ per group).

We also tested for cocaine-induced place conditioning in the rats exposed to VEH, MPH, FLX, or MPH + FLX as juveniles and assigned to the long-term condition (i.e., 2 months after the last drug injection) (Fig. 2B). No conditioning effects were detected in rats conditioned with saline regardless of juvenile drug pretreatment. Time spent in the cocaine-paired compartments varied as a function of juvenile drug treatment $\left(F_{(3,65)}=17.1 ; p<\right.$ $0.01)$, cocaine dose $\left(F_{(2,65)}=5.8 ; p<0.01\right)$, and the interaction between the two variables $\left(F_{(6,65)}=8.2 ; p<0.01\right)$. As expected, $\mathrm{VEH}$-pretreated rats conditioned to the cocaine-paired compartments in a dose-dependent manner ( $p<0.05 ; n=6-7$ per group), whereas the MPH-pretreated rats avoided the cocaine-paired compartments regardless of dose when compared with the VEHpretreated controls ( $p<0.05 ; n=5-8$ per group). The FLX- and $\mathrm{MPH}+$ FLX-pretreated rats ( $n=5-8$ per group) readily conditioned to the cocaine-paired compartments in a dose-dependent manner when compared with the VEH-pretreated controls $(p<0.05)$. Interestingly, further analysis indicated that the magnitude of place conditioning developed by the MPH + FLXpretreated rats was significantly higher when compared with the FLX-treated group at both cocaine doses $(p<0.05)$, indicating that combined MPH + FLX pretreatment potentiated the effects of cocaine in this behavioral task.
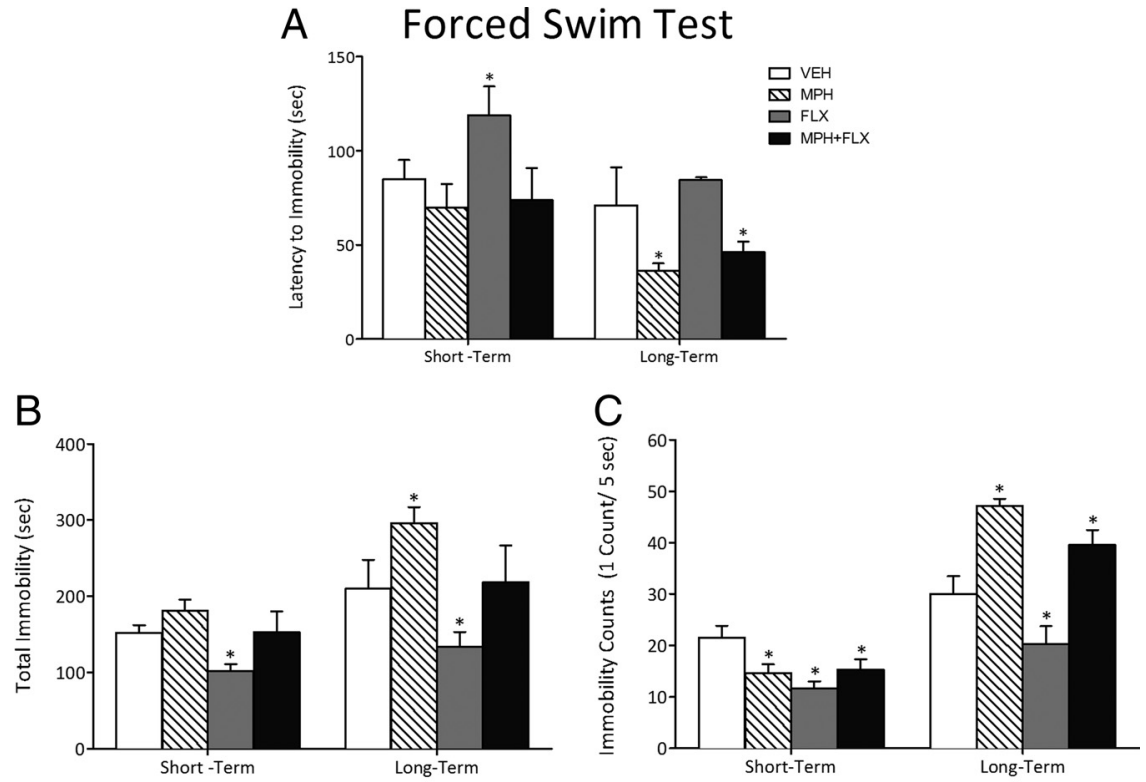

D
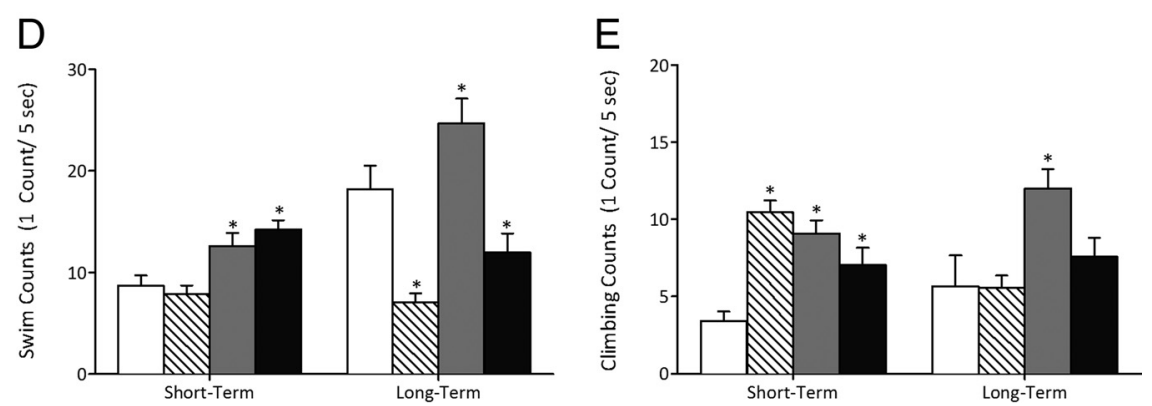

Figure 5. Effects of juvenile exposure to VEH, MPH, FLX, or MPH + FLX on forced-swimming behaviors short term (24h after the last injection; $n=7-8$ per group) and long term ( 2 months after the last injection; $n=6-8$ per group). $A-E$, Latency to become immobile $(\boldsymbol{A})$, total immobility $(\boldsymbol{B})$, immobility counts $(\boldsymbol{C})$, swim counts $(\boldsymbol{D})$, and climbing counts $(\boldsymbol{E})$ of rats tested in the forcedswim test after chronic juvenile treatment with VEH, MPH, FLX, or MPH + FLX. *Significantly different from the VEH-pretreated controls $(p<0.05)$. Data are presented as latencies to become immobile and total immobility (in seconds), and as cumulative $5 \mathrm{~s}$ intervals of swimming and immobility counts (mean $\pm \mathrm{SEM}$ ).

\section{Sucrose preference}

We then assessed sensitivity to a natural reward, namely sucrose, 2 months after juvenile exposure to VEH, MPH, FLX, or $\mathrm{MPH}+\mathrm{FLX}$ using the sucrose preference test on a separate group of rats (Fig. 3) ( $N=40 ; 9-11$ per group). Juvenile drug preexposure did not influence total fluid intake (water + sucrose) (Fig. $3 B$ ) in adulthood $(p>0.05)$. However, a repeatedmeasures ANOVA indicated that preference for sucrose varied as a function of juvenile drug treatment $\left(F_{(3,144)}=15.7 ; p<0.01\right)$, sucrose concentration $\left(F_{(4,144)}=173.8 ; p<\right.$ $0.01)$, and the interaction between the two independent variables $\left(F_{(12,144)}=3.5 ; p<\right.$ $0.05)$. MPH pretreatment decreased preference for sucrose at the $0.125,0.25$, and $0.5 \%$ concentrations $(p<0.05)$, whereas FLX pretreatment increased sucrose preference only at the $0.5 \%$ concentration when compared with the VEH-pretreated controls $(p<0.05)$. MPH + FLX pretreatment increased preference for sucrose at both the 0.5 and $1.0 \%$ concentrations when compared with the VEH-pretreated controls $(p<0.05)$.

Effects of juvenile MPH, FLX, and MPH + FLX exposure on aversive stimuli Elevated plus maze

The short- and long-term effects of juvenile drug exposure (VEH, MPH, FLX, or $\mathrm{MPH}+\mathrm{FLX}$ ) on behavioral response to anxiogenic stimuli are shown in Figure 4. The percentage time spent in the open arms of the elevated plus maze varied as a 
function of juvenile drug pretreatment $24 \mathrm{~h}$ after the last injection $\left(F_{(3,26)}=3.0\right.$; $p<0.05$ ) (Fig. 4, left panel). MPH pretreatment decreased time spent in the open arms, whereas FLX and MPH + FLX pretreatment did not influence behavioral responding on this task when compared with the VEH-pretreated controls ( $p>$ $0.05 ; N=30 ; 7-8$ per group).

We then assessed the long-term effects of juvenile VEH, MPH, FLX, or MPH + FLX exposure on anxiety-like behavior in separate groups of rats (Fig. 4, right panel) $(N=40 ; 8-12$ per group). The percentage time spent in the open arms of the elevated plus maze was affected by juvenile drug pretreatment $\left(F_{(3,36)}=12.9 ; p<\right.$ 0.001). MPH-, FLX-, and MPH + FLXpretreated rats spent significantly less time in the open arms when compared with the VEH-treated controls $(p<0.05)$.

\section{Forced swimming}

We used the forced-swim test to assess rats' responsiveness to behavioral despair $24 \mathrm{~h}$ after juvenile VEH, MPH, FLX, or MPH + FLX treatment $(N=30)$ or when they reached adulthood $(N=30)$ (Fig. 5). Juvenile drug treatment influenced rats' latency to become immobile $\left(F_{(3,26)}=4.6 ; p<\right.$ $0.05)$, total immobility $\left(F_{(3,26)}=4.0 ; p<\right.$ $0.05)$, and counts of immobility $\left(F_{(3,26)}=4.7\right.$; $p<0.01)$, swimming $\left(F_{(3,26)}=8.3 ; p<\right.$ $0.05)$, and climbing $\left(F_{(3,26)}=14.8 ; p<\right.$ $0.05)$ when tested $24 \mathrm{~h}$ after the last injection (Fig. 5A-E, left panels) ( $n=7-8$ per group). Specifically, MPH pretreatment had no effect on latency to immobility, total immobility, or swimming counts $(p>0.05)$, but decreased immobility and increased climbing counts when compared with the VEHpretreated controls $(p<0.05)$. Conversely, FLX pretreatment increased latency to immobility and decreased total immobility, while increasing swimming and climbing and decreasing immobility counts when compared with the VEH-pretreated controls $(p<0.05)$. Combined MPH + FLX pretreatment did not affect latency to immobility or total immobility $(p>0.05)$, but increased swimming and climbing, while decreasing immobility counts when compared with the VEH-pretreated controls $(p<0.05)$.

Separate groups of rats were treated with VEH, MPH, FLX, or $\mathrm{MPH}+\mathrm{FLX}$ as juveniles and exposed to the forced-swim behavioral task in adulthood (Fig. $5 A-E$, right panels). Separate oneway ANOVAs revealed significant differences in latency to become immobile $\left(F_{(3,26)}=8.4 ; p<0.01\right)$, total immobility $\left(F_{(3,26)}=7.5 ; p<0.01\right)$, and counts of immobility $\left(F_{(3,26)}=16.2\right.$; $p<0.01)$, swimming $\left(F_{(3,26)}=15.1 ; p<0.01\right)$, and climbing $\left(F_{(3,26)}=5.0 ; p<0.05\right)$ as a function of juvenile drug pretreatment ( $n=6-8$ per group). MPH pretreatment decreased latency to immobility $(p<0.05)$, increased total immobility $(p<0.05)$, decreased swimming $(p<0.05)$, and increased immobility counts $(p<0.05)$, without affecting climbing counts $(p>0.05)$, when compared with the VEH-pretreated controls. FLX pretreat-

\section{Short-Term mRNA}

B CREB $\quad$ C

C BDNF
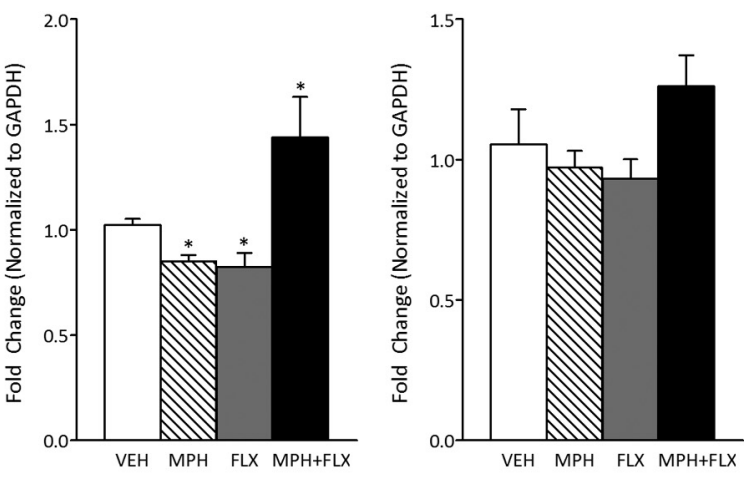

E

Zif268

$\mathrm{F}$

mTOR
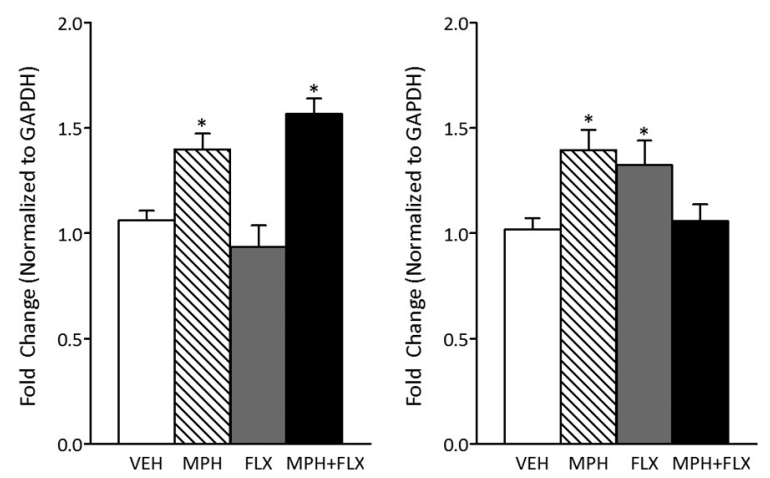

Figure 6. Short-term effects of juvenile exposure to VEH, MPH, FLX, or MPH + FLX on ERK-related gene expression within the VTA $24 \mathrm{~h}$ after the last injection ( $n=8$ per group). $\boldsymbol{A}$, ERK2 mRNA was decreased after MPH and FLX treatment $(p<0.05)$, but MPH $(p<0.05)$, but did not vary after MPH + FLX exposure when compared with the VEH-pretreated controls. *Significantly different from the VEH-pretreated controls $(p<0.05)$. Data are presented as fold change normalized to GAPDH (mean \pm SEM).

ment decreased total immobility $(p<0.05)$ without affecting latency to immobility $(p>0.05)$, but increased swimming and climbing while decreasing immobility counts when compared with the VEH-pretreated controls $(p<0.05)$. MPH + FLX pretreatment significantly decreased latency to immobility (interpreted as increased susceptibility to stress; $p<0.05$ ), had no effect on total immobility $(p>0.05)$, but decreased swimming and increased immobility $(p<0.05)$, but not climbing counts $(p>$ $0.05)$, when compared with the VEH-pretreated controls.

\section{Effects of juvenile MPH, FLX, and MPH + FLX exposure on ERK signaling in the VTA}

ERK-related gene expression within the VTA was assessed $24 \mathrm{~h}$ after juvenile exposure to VEH, MPH, FLX, or MPH + FLX using qPCR (Fig. 6) $\left(N=32 ; 8\right.$ per group). $\operatorname{ERK} 2\left(F_{(3,28)}=28.14 ; p<\right.$ $0.01)$ (Fig. 6A), $\operatorname{CREB}\left(F_{(3,28)}=31.7 ; p<0.01\right)$ (Fig. $\left.6 B\right)$, Zif268 $\left(F_{(3,28)}=14.5 ; p<0.01\right)$ (Fig. $\left.6 E\right)$, and $\operatorname{mTOR}\left(F_{(3,28)}=5.0 ; p<\right.$ 0.05 ) (Fig. $6 F$ ) mRNA varied as a function of juvenile drug exposure $24 \mathrm{~h}$ after treatment, whereas $\operatorname{BDNF}(p>0.05)$ (Fig. $6 C$ ) and c-Fos $(p>0.05)$ (Fig. $6 D)$ were not affected at this time point. $\mathrm{MPH}$ pretreatment had no effect on BDNF or c-Fos $(p>0.05)$, but decreased ERK2 $(p<0.05)$ and CREB $(p<0.05)$ while increasing Zif268 and mTOR mRNA ( $p<0.05$, respectively) when compared with the VEH-pretreated controls. FLX pretreat- 
Long-Term mRNA

A

ERK2

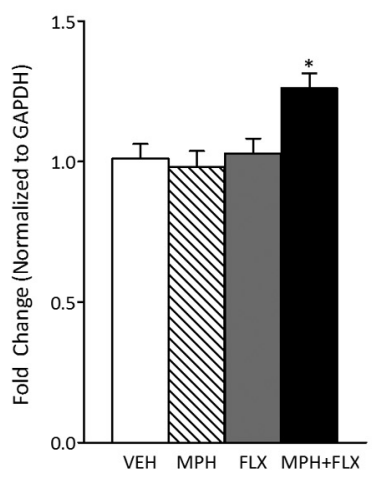

D c-Fos

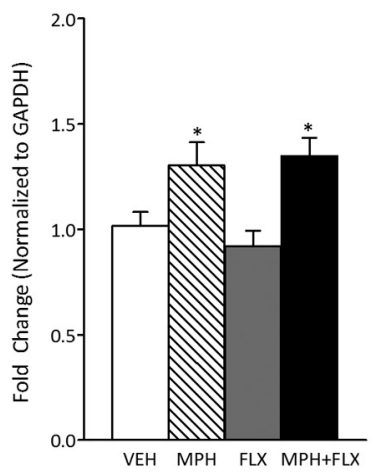

B

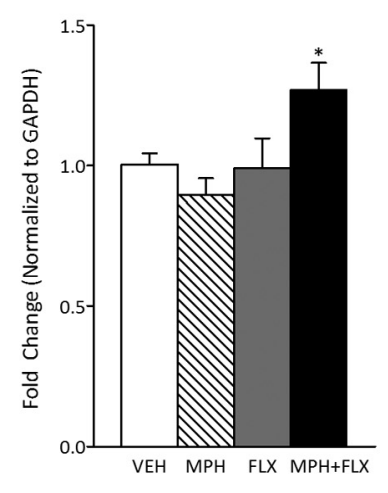

E

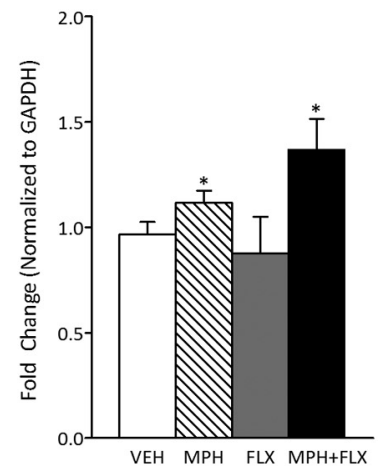

C

BDNF

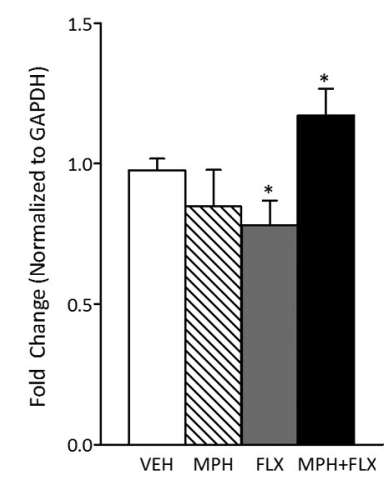

$\mathrm{F}$

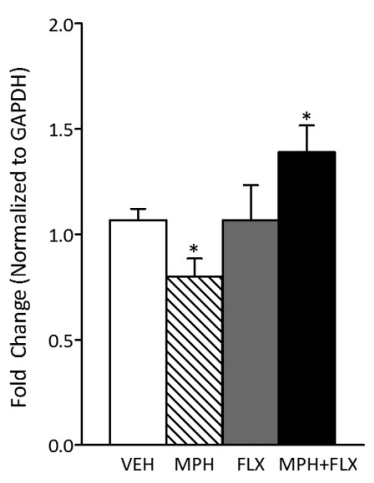

Figure 7. Long-term effects of juvenile exposure to $\mathrm{VEH}, \mathrm{MPH}, \mathrm{FLX}$, or MPH + FLX on ERK-related gene expression within the VTA 2 months after the last injection ( $n=8$ per group). $\boldsymbol{A}, \boldsymbol{B}, \operatorname{ERK2}(\boldsymbol{A}), \mathrm{CREB}(\boldsymbol{B}) \mathrm{mRNA}$ increased after MPH $+\mathrm{FLX}(p<0.05)$, but not after MPH or FLX $(p>0.05)$ when compared with the VEH-pretreated rats. C, BDNF mRNA did not vary after MPH $(p>0.05)$, but was decreased following FLX, and increased after MPH $+F L X$ exposure $(p<0.05$, respectively) when compared with the VEH-pretreated controls. $\boldsymbol{D}, c-$ Fos mRNA was increased after MPH and MPH $+F L X(p<0.05)$, but did not vary after FLX treatment $(p>0.05)$ when compared with the VEH-pretreated controls. E, Zif268 mRNA was increased following MPH and MPH + FLX ( $p<$ 0.05), but not FLX $(p>0.05)$ when compared with the VEH-pretreated controls. $F$, mTOR mRNA was decreased by MPH and increased by MPH $+F L X(p<0.05)$, but did not vary after FLX exposure $(p>0.05)$ when compared with the VEH-pretreated controls. *Significantly different from VEH-pretreated controls $(p<0.05)$. Data are presented as fold change normalized to GAPDH (mean \pm SEM).

ment decreased ERK2 $(p<0.05)$ and CREB $(p<0.05)$ and increased mTOR mRNA $(p<0.05)$, while having no effect on BDNF, c-Fos, or Zif268 mRNA when compared with the VEHpretreated controls $(p>0.05)$. MPH + FLX pretreatment increased ERK2, CREB, and Zif268 mRNA ( $p<0.05$, respectively), but had no effect on BDNF, c-Fos, or mTOR mRNA when compared with the VEH-pretreated controls $(p>0.05)$.

Figure 7 shows the effects of VEH, MPH, FLX, and MPH + FLX on ERK-related gene expression 2 months after juvenile drug exposure $(N=32 ; 8$ per group). Separate one-way ANOVAs indicated that $\operatorname{ERK} 2\left(F_{(3,28)}=5.6 ; p<0.01\right)$ (Fig. $\left.7 A\right)$, $\operatorname{CREB}\left(F_{(3,28)}=\right.$ $3.9 ; p<0.05)$ (Fig. $7 B), \operatorname{BDNF}\left(F_{(3,28)}=3.4 ; p<0.05\right.$ ) (Fig. $7 C)$, c-Fos $\left(F_{(3,28)}=6.1 ; p<0.01\right)$ (Fig. $\left.7 D\right)$, Zif268 $\left(F_{(3,28)}=3.2\right.$; $p<0.05)$ (Fig. $7 E)$, and $\operatorname{mTOR}\left(F_{(3,28)}=4.4 ; p<0.05\right)($ Fig. $7 F)$ mRNA varied as a function of juvenile drug pretreatment. More specifically, MPH had no effect on ERK2, CREB, or BDNF mRNA when compared with the VEH-pretreated controls ( $p>$ $0.05)$. Nevertheless, MPH pretreatment increased c-Fos $(p<$ $0.05)$ and Zif268 $(p<0.05)$, while decreasing mTOR $(p<0.05)$ mRNA when compared with the VEH-pretreated controls. FLX pretreatment decreased BDNF $(p<0.05)$, without affecting ERK2, CREB, c-Fos, Zif268, or mTOR mRNA when compared

with the VEH-pretreated controls $(p>$ 0.05). $\mathrm{MPH}+$ FLX pretreatment increased ERK2, CREB, BDNF, c-Fos, Zif268, and mTOR mRNA when compared with the VEH-pretreated controls $(p<0.05$, respectively).

We further assessed the activity of ERK signaling 2 months after VEH or MPH + FLX juvenile exposure as inferred from the phosphorylation of ERK2 protein and two downstream targets, CREB and mTOR (Fig. 8 ) ( $N=16$; 8 per group). $\mathrm{MPH}+$ FLX exposure increased levels of phosphorylated ERK2 $\left(t_{(14)}=2.3\right.$; $p<$ 0.05) (Fig. $8 A$ ), CREB $\left(t_{(14)}=4.6 ; p<\right.$ $0.01)$ (Fig. $8 B$ ), and mTOR $\left(t_{(14)}=2.0\right.$; $p<0.05$ ) (Fig. 8C) protein within the VTA when compared with the VEHpretreated controls (all normalized to GAPDH ). No changes in total ERK2, total CREB, total mTOR, or GAPDH protein levels were detected when compared with the VEH-pretreated controls ( $p>0.05)$.

\section{Reversal of combined MPH + FLX-} induced behavioral deficits in adulthood Based on the ability of juvenile MPH + FLX treatment to increase ERK2 signaling within the VTA in adulthood, and since increasing ERK activity increases susceptibility to stress (Iñiguez et al., 2010b), it was of interest to assess the functional consequences of decreasing ERK activity in this brain region on behavioral despair, namely the forced-swim behavioral task. To this end, ERK2 signaling was reduced within the VTA of adult rats pretreated with MPH + FLX as juveniles by local injection of HSV-dnERK2 and responsivity to behavioral despair was assessed. We also tested five additional control groups as follows: VEH-pretreated rats plus sham surgery, HSV-GFP, and HSV-dnERK2, and MPH + FLX-pretreated rats plus sham surgery, and HSV-GFP.

\section{Validation of viral-mediated gene transfer in the VTA}

Figure $9 A$ shows the region of the VTA to which sham or microinjections of HSV vectors (HSV-GFP or -dnERK2) were targeted. As reported previously, viral-encoded transgene expression was maximal between days 3 and 4 after injection (data not shown), significantly declining thereafter, and undetectable 1 week after the microinjection (Carlezon et al., 1997; Barrot et al., 2002; Olson et al., 2005). Confocal microscopy (Fig. $9 B-D$ ) revealed that the percentage of $\mathrm{TH}$-positive neurons overexpressing GFP in the VTA $(\sim 55 \%)$ was similar to previous findings (Olson et al., 2005; Russo et al., 2007) with no detectable expression of the viralencoded transgenes in glial cells (data not shown).

Blockade of ERK2 activity in the VTA reverses MPH + FLXinduced behavioral reactivity to forced-swimming stress The effects of virus surgery (sham, HSV-GFP, and HSV-dnERK2) after juvenile exposure to VEH, MPH, FLX, or MPH + FLX on day 2 of forced swimming are shown in Figure $9(N=47,6-10$ per group). The amount of time rats engaged in escape-directed behav- 
iors in the forced-swim test varied as a function of viral posttreatment. Specifically, latency to immobility varied as a function of virus posttreatment $\left(F_{(5,42)}=8.6 ; p<\right.$ 0.001) (Fig. 9E). VEH-pretreated rats receiving microinjections of HSV-dnERK2, but not HSV-GFP, demonstrated significantly higher latencies to immobility (interpreted as increased resilience to stress) when compared with the VEH-pretreated/sham controls $(p<0.05)$. MPH + FLX-pretreated rats receiving sham surgery or HSV-GFP posttreatment had lower latencies to become immobile when compared with the VEH-pretreated/sham controls $(p<0.05)$. However, the latency to immobility demonstrated by the $\mathrm{MPH}+$ FLX-pretreated rats microinjected with HSV-dnERK2 was increased when compared with the MPH + FLXpretreated rats receiving sham surgery or HSV-GFP within the VTA $(p<0.05$, respectively). Further analyses indicated that total immobility $\left(F_{(5,42)}=8.5 ; p<\right.$ $0.001)$ (Fig. $9 F)$ and immobility counts $\left(F_{(5,42)}=4.7 ; p<0.002\right)$ (Fig. $9 G$, left panel) also varied as a function of virus posttreatment. However, behavioral counts of swimming and climbing did not reach statistical significance (Fig. 9G, middle and right panels, respectively) $(p>0.05)$. VEHpretreated rats receiving either microinjections of HSV-GFP or HSV-dnERK2 did not differ from the VEH-pretreated/sham controls $(p>0.05)$. MPH + FLX-pretreated rats receiving sham surgery or HSV-GFP had significantly higher levels of total immobility $(p<0.05)$ and increased immobility counts $(p<0.05)$ when compared with the VEH-pretreated/sham controls. Conversely, MPH + FLX-pretreated rats microinjected with HSVdnERK2 did not differ from the VEH-pretreated/sham controls in total immobility or immobility counts when compared with the VEH-pretreated/sham controls $(p>0.05)$, but demonstrated decreased total immobility and lower immobility counts $(p<$ 0.05 , respectively) when compared with the MPH + FLXpretreated rats receiving HSV-GFP within the VTA, indicating that viral-mediated blockade of ERK2 activity with HSV-dnERK2 reversed the effects of MPH + FLX pretreatment on measures of behavioral despair.

A separate group of VEH- and $\mathrm{MPH}+$ FLX-pretreated rats receiving sham, HSV-GFP, or HSV-dnERK2 into the VTA ( $n=$ 4-5 per group) were tested in the open field $1 \mathrm{~d}$ after exposure to swimming stress to assess general locomotor activity (Fig. 9H). No significant differences were apparent between the groups when locomotor activity was assessed $24 \mathrm{~h}$ after day 1 of forced swimming $(p>0.05)$.

\section{Discussion}

This study assessed the neurobiological consequences of concomitant exposure to MPH and FLX, two drugs that are often combined for the management of comorbid ADHD and MDD in pediatric populations (Bhatara et al., 2004). We show that chronic juvenile administration of MPH, FLX, or MPH + FLX alters responsiveness to both rewarding and aversive situations, and disrupts VTA ERK2 expression/signaling. Blockade of VTA
Long-Term Protein Phosphorylation

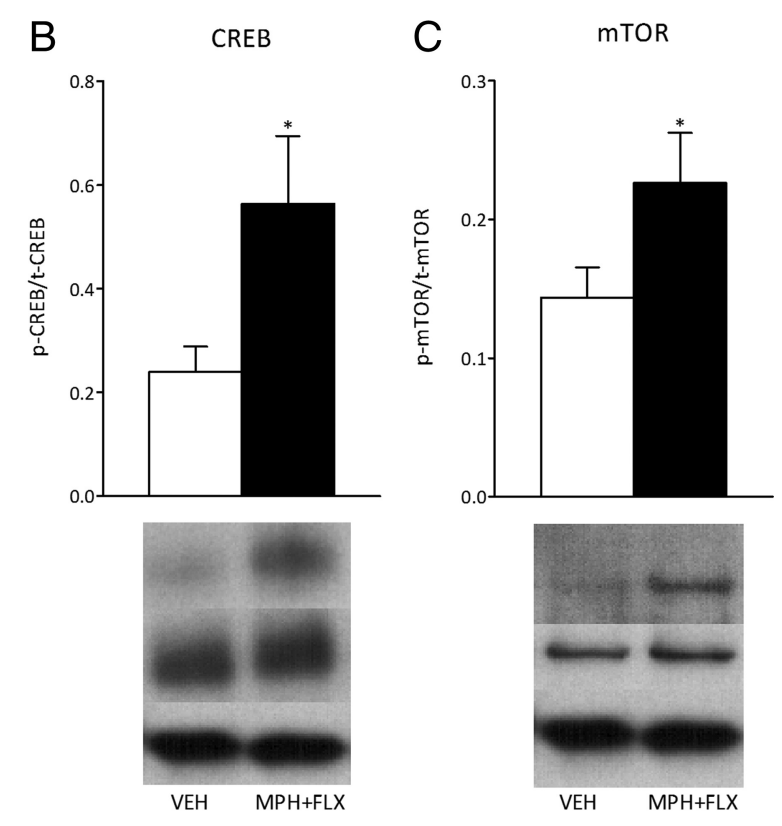

igure 8. Long-term effects of juvenile exposure to VEH, MPH, FLX, or MPH + FLX on protein phosphorylation within the VTA months after the last injection ( $n=8$ per group). Exposure to MPH + FLX significantly increased the levels of phospho (p) ERK2 , and $p$-mTOR proteins $(p<0.05$, respectively) $(\boldsymbol{C})$ without affecting total (t) levels of protein when compared with the VEH-pretreated controls. *Significantly different from the VEH-pretreated controls $(p<0.05)$. Data are presented as a ratio of total protein normalized to GAPDH (mean \pm SEM).

ERK2 activity rescued the MPH + FLX-induced behavioral deficits in forced swimming, like administration of antidepressants (Lucki, 1997; Iñiguez et al., 2010a).

Juvenile exposure to MPH, FLX, or MPH + FLX changed responsivity to appetitive stimuli. MPH pretreatment reduced, whereas FLX and MPH + FLX pretreatment increased sensitivity to cocaine place conditioning. Interestingly, MPH + FLX pretreatment induced conditioned place preference at a dose that had no effect in the VEH- or FLX-pretreated rats $(5 \mathrm{mg} / \mathrm{kg})$, suggesting that MPH + FLX enhances sensitivity to drug reward. The long-term effects were particularly striking: while MPH pretreatment induced a significant aversion to cocaine, the FLX- and $\mathrm{MPH}+\mathrm{FLX}$-pretreated rats readily preferred the cocaine-paired compartments. Similarly, MPH blunted, while FLX and MPH + FLX pretreatments increased sucrose preference in adulthood, likely by changing sensitivity to reward, since total liquid consumption did not differ. Interestingly, the effects of MPH + FLX were not intermediate, since MPH decreased preference for sucrose. This suggests that FLX is not simply reversing the MPHinduced deficits, but that FLX may interact with MPH to increase sensitivity to both drug and natural rewards. These findings support reports demonstrating that exposure to MPH or FLX during early life leads to long-lasting adaptations in brain reward pathways (Mague et al., 2005; Thanos et al., 2007; Iñiguez et al., 2010a) and suggest that concurrent exposure may enhance this effect (Steiner et al., 2010). Although we demonstrate that MPH + FLX pretreatment increased sensitivity to reward, this is not necessarily maladaptive and may not represent enhanced addiction potential (Tzschentke, 1998).

Our findings also indicate that juvenile MPH, FLX, and $\mathrm{MPH}+\mathrm{FLX}$ treatment influences rats' responsiveness to anxietyand stress-inducing situations. Short-term, MPH pretreatment en- 
A
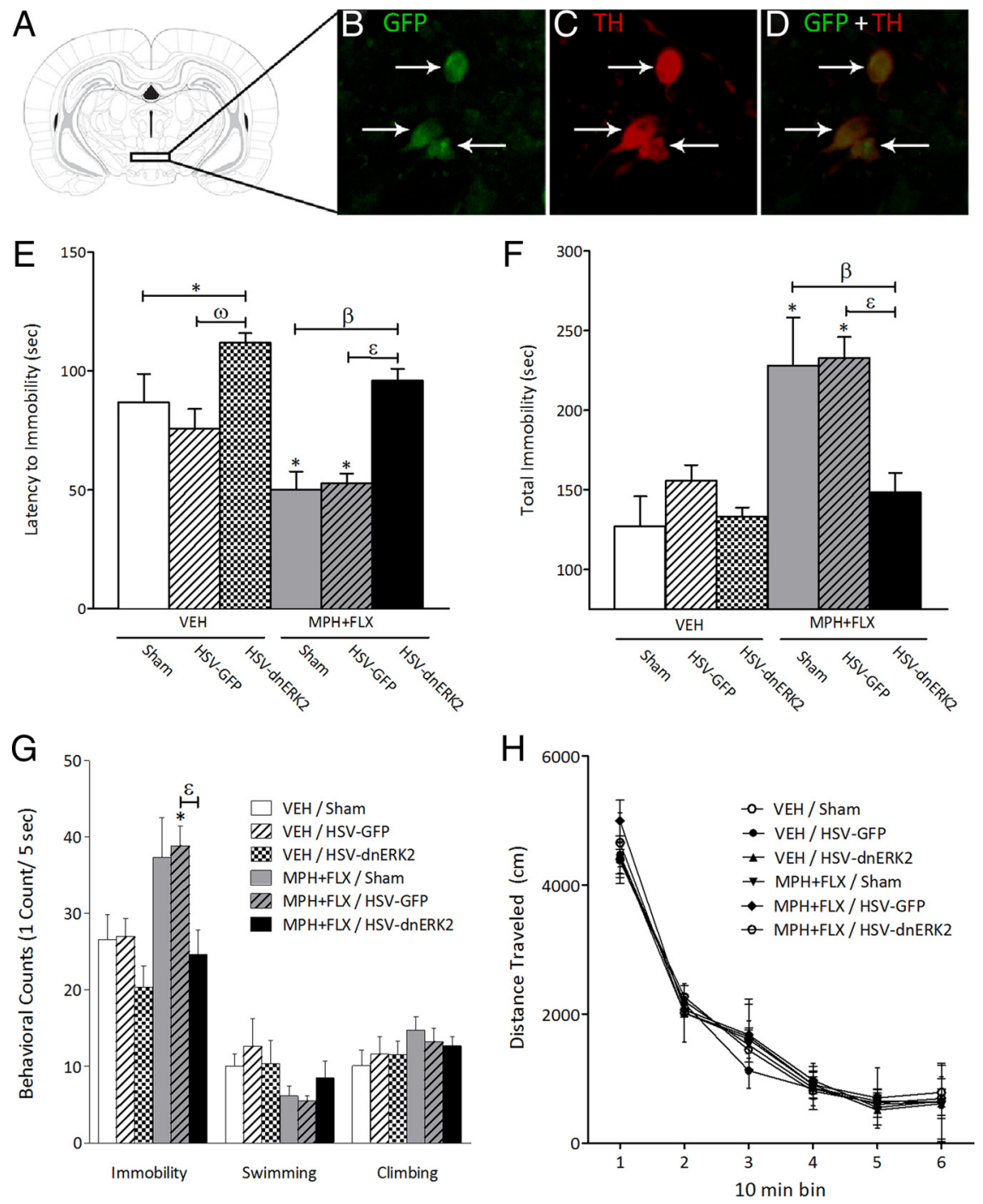

Figure 9. Viral-mediated blockade of ERK2 in the rat VTA regulates behavioral responses to forced-swim stress. $\boldsymbol{A}$, Region of VTA to which microinjections of HSV vectors were targeted (Paxinos and Watson, 1997). $\boldsymbol{B}$, Cells expressing dnERK2 (green, cyanine 2) fluorescence. $\boldsymbol{C}$, Cells expressing TH (red, cyanine 3) fluorescence. $\boldsymbol{D}$, Merged image of $\boldsymbol{B}$ and $\boldsymbol{C}$ showing dual-labeled neurons in the VTA (magnification, $400 \times$; $\sim 5 \mathrm{~mm}$ caudal to bregma). The arrows indicate labeled cells. VEH-pretreated rats receiving microinjections of HSV-dnERK2 in the VTA demonstrated higher latency to immobility $(p<0.05)(\boldsymbol{E})$, without affecting total immobility $(\boldsymbol{F})$, or forced-swimming behavioral counts $(\boldsymbol{G})$ when compared with VEH-pretreated/sham controls $(p>0.05$, respectively). MPH + FLX-pretreated rats receiving sham surgery or HSV-GFP had decreased latency to immobility $(\boldsymbol{E})$, with increased total immobility $(\boldsymbol{F})$ and immobility counts (G, left panel) when compared with the VEH-pretreated/sham and VEH-pretreated/HSV-GFP controls $(p<0.05$, respectively). MPH + FLX-pretreated rats receiving HSV-dnERK2 did not differ in any of the dependent variables when compared with the VEH-pretreated/sham controls ( $p>0.05 ; n=6-10$ per group). $\boldsymbol{H}$, Distance traveled in the open field $24 \mathrm{~h}$ after day 1 of forced swimming was not affected by viral surgery or by MPH + FLX pretreatment when compared with VEHpretreated/sham controls. *Significantly different from the VEH-pretreated/sham controls $(p<0.05)$. ${ }^{\omega}$ Significantly different from the VEH-pretreated/HSV-GFP controls $(p<0.05) .{ }^{\beta}$ Significantly different from MPH + FLX-pretreated/sham $(p<0.05)$. ${ }^{\varepsilon}$ Significantly different from MPH + FLX-pretreated/HSV-GFP $(p<0.05)$. Data are presented as latencies to become immobile and total immobility (in seconds), as cumulative 5 s intervals of immobility, swimming, and climbing counts, and as distance traveled in centimeters (mean \pm SEM).

hanced reactivity to the elevated plus maze, whereas FLX or MPH + FLX did not. Conversely, MPH, FLX, and MPH + FLX pretreatments enhanced responsivity to anxiogenic stimuli long term. This is not surprising, since juvenile exposure to MPH or FLX has been shown to induce an anxiogenic phenotype in adulthood (Bolaños et al., 2003b; Karpova et al., 2009; Iñiguez et al., 2010a). Forcedswimming results showed that MPH and MPH + FLX did not influence behavioral despair, whereas FLX induced a stress-resistant phenotype $24 \mathrm{~h}$ after treatment (Iñiguez et al., 2010a). As adults,
MPH- and MPH + FLX-pretreated rats showed enhanced susceptibility to swimming stress, whereas FLX-pretreated rats showed decreased vulnerability. Together, these data support evidence that juvenile exposure to $\mathrm{MPH}$ induces enduring vulnerability to stress (Lagace et al., 2006; Halladay et al., 2009; Wiley et al., 2009), while FLX exposure results in an anxiogenic and stressresistant behavioral phenotype in adulthood (Karpova et al., 2009; Iñiguez et al., 2010a). We now extend these findings to combined juvenile MPH + FLX exposure. While the forced-swim test is a valid and reliable animal model, results can be variable across its dependent measures (Reed et al., 2008; Iñiguez et al., 2009). Long-term, $\mathrm{MPH}+$ FLX-pretreated rats did not show substantial change in total immobility, but did show a "depression-like" behavioral profile in latency to immobility, swimming, and immobility counts. Furthermore, a separate group of MPH + FLX-pretreated rats receiving sham or HSV-GFP surgeries showed increased total immobility (Fig. 9F).

The mechanism(s) underlying these behavioral effects are unknown. Given the pharmacodynamic properties of $\mathrm{MPH}$ and FLX and that dopamine and serotonin systems interact (Benloucif et al., 1993; De Deurwaerdère et al., 1996; Bolaños et al., 2002), it has been suggested that concurrent use of these drugs may induce cocaine-like effects (Yano and Steiner, 2007). In line with this hypothesis, acute $\mathrm{MPH}+\mathrm{FLX}$ or cocaine treatment in adult rats have similar biochemical and behavioral effects (Borycz et al., 2008; Van Waes et al., 2010). Cocaine also induces anxietyand depression-like behaviors in juvenile and adult rats (Blanchard and Blanchard, 1999; Perrine et al., 2008). However, juvenile cocaine exposure decreases sensitivity to cocaine in adulthood (Carlezon et al., 2003), an effect opposite to our finding following $\mathrm{MPH}+$ FLX pretreatment. This finding may discount the suggestion that MPH + FLX acts as a cocaine mimetic but supports a view that, when combined, MPH + FLX induces complex effects distinct from MPH, FLX, or cocaine alone. Accordingly, MPH + FLX treatment did not enhance the effects of either drug across all behavioral measures. Specifically, MPH + FLX induced a behavioral profile similar to FLX $24 \mathrm{~h}$ after treatment. When tested in adulthood, MPH + FLX induced a behavioral phenotype distinctive from either MPH or FLX alone: MPH + FLX increased vulnerability to stress (like MPH-pretreated rats) and enhanced sensitivity to both cocaine and sucrose rewards (like FLX-pretreated rats). Therefore, it is unlikely that one drug is simply enhancing the effects of the other, and differences in dosing, age, length of drug exposure, metabolism, as well as the complex interaction between two com- 
plicated and poorly understood drug pathways must be considered (Bolaños et al., 1998; Carlezon and Konradi, 2004).

We also measured the expression of ERK-driven signaling molecules within the VTA after juvenile drug treatment, since MPH and FLX interact with the VTA and the nucleus accumbens (Yang et al., 2006; Sekine et al., 2007), neural substrates mediating responses to rewarding and aversive stimuli (Nestler and Carlezon, 2006; Wallace et al., 2009; LaPlant et al., 2010). We show that ERK2/CREB mRNA was decreased by MPH or FLX alone, but unexpectedly elevated by combined MPH + FLX $24 \mathrm{~h}$ after treatment, while increases in CREB and Zif268 mRNA in MPH + FLX-pretreated rats accompanied increased ERK2 mRNA (Turgeon et al., 1997; McClung and Nestler, 2003). Surprisingly, ERK2 mRNA was upregulated 2 months after MPH + FLX exposure. This is particularly interesting because neither MPH nor FLX induced similar increases when administered alone, suggesting long-lasting differences between combined and individual pretreatments. Whether this effect is due to drug-induced ontogenetic changes is unknown; however, in adult rodents chronic exposure to psychostimulants increases ERK activity, resulting in CREB activation and the subsequent transcription of c-Fos and Zif268 (Lu et al., 2006), while FLX exposure decreases ERK phosphorylation and reduces CREB activation (Fumagalli et al., 2005; Böer et al., 2010). Together, these results underscore the complexity of drug-induced effects in the immature brain, and detailed assessments of these phenomena are needed. Because increased gene expression does not necessarily result in increased protein levels and may not represent increased activity of these enzymes (Lee et al., 2003; Mehra et al., 2003), we assessed phosphorylation levels of key ERK-related proteins 2 months after juvenile MPH + FLX exposure. We found increased phosphorylation of ERK2, CREB, and mTOR proteins within the VTA, with no change in total levels of these proteins. Given reports implicating mTOR activity within the prefrontal cortex in the antidepressant effects observed after ketamine treatment (Li et al., 2010), MPH + FLX-induced mTOR activity may seem counterintuitive. However, manipulations of ERK-related molecules in different brain regions often result in varying behavioral effects (Berton et al., 2006; Krishnan et al., 2007). Thus, a prodepressant behavioral phenotype and increased mTOR activity within the VTA after MPH + FLX treatment is not surprising, but does require further analysis.

We further demonstrate a role for ERK in the MPH + FLXinduced behavioral effects by decreasing ERK2 activity within the VTA of MPH + FLX-pretreated rats, using viral-mediated gene transfer. Decreased ERK2 activity rescued the prodepressant $\mathrm{MPH}+$ FLX-induced phenotype by increasing escape-like behaviors in the forced-swim test, effects similar to those elicited by antidepressant treatments (Cryan et al., 2002). This did not result from deficits in motor activity because viral treatment did not affect basal locomotion (Fig. 9H). These findings mirror reports that stress increases ERK2 signaling within the VTA (Iñiguez et al., 2010b), and that overexpressing ERK2 (Iñiguez et al., 2010b), or infusing BDNF (Eisch et al., 2003; Lu et al., 2004) in the VTA induces anxiety- and depression-like states while enhancing drug reward (Bolaños and Nestler, 2004; Iñiguez et al., 2010c). Additionally, increased VTA-ERK activity after MPH + FLX supports the notion that concurrent treatment with these drugs may be pharmacodynamically similar to treatment with cocaine (Yano and Steiner, 2007; Steiner et al., 2010) and suggests that combining MPH and FLX early in life may lead to life-long behavioral and biochemical abnormalities. Importantly, the present study did not assess reward-related behavior following viral manipula- tion of ERK2 signaling. Recently, we have shown that HSV-ERK2 modulates responsiveness to cocaine reward (Iñiguez et al., 2010c), but whether viral knockdown of ERK2 would reverse $\mathrm{MPH}+$ FLX-induced sensitivity to reward remains unknown.

In summary, our study shows that juvenile exposure to combined MPH + FLX increases sensitivity to reward, anxiety- and stress-eliciting situations later in life, and implicates dysregulated ERK signaling within the VTA as a potential mechanism underlying these effects. It is imperative to note, however, that the MPH + FLX-induced effects described in this study were derived from "normal" animals, and similar MPH + FLX treatment in an animal model of ADHD/MDD comorbidity might yield different results. Furthermore, studies assessing potentially enduring side effects of MPH + FLX in humans are lacking (Daviss, 2008), making interpretative parallels challenging. Our findings necessitate further study into the effects of early life drug exposure on functional outcomes in adulthood.

\section{References}

Andersen SL, Navalta CP (2004) Altering the course of neurodevelopment: a framework for understanding the enduring effects of psychotropic drugs. Int J Dev Neurosci 22:423-440.

Andersen SL, Arvanitogiannis A, Pliakas AM, LeBlanc C, Carlezon WA Jr (2002) Altered responsiveness to cocaine in rats exposed to methylphenidate during development. Nat Neurosci 5:13-14.

Barrot M, Olivier JD, Perrotti LI, DiLeone RJ, Berton O, Eisch AJ, Impey S, Storm DR, Neve RL, Yin JC, Zachariou V, Nestler EJ (2002) CREB activity in the nucleus accumbens shell controls gating of behavioral responses to emotional stimuli. Proc Natl Acad Sci U S A 99:11435-11440.

Benloucif S, Keegan MJ, Galloway MP (1993) Serotonin-facilitated dopamine release in vivo: pharmacological characterization. J Pharmacol Exp Ther 265:373-377.

Berton O, McClung CA, Dileone RJ, Krishnan V, Renthal W, Russo SJ, Graham D, Tsankova NM, Bolanos CA, Rios M, Monteggia LM, Self DW, Nestler EJ (2006) Essential role of BDNF in the mesolimbic dopamine pathway in social defeat stress. Science 311:864-868.

Bhatara V, Feil M, Hoagwood K, Vitiello B, Zima B (2004) National trends in concomitant psychotropic medication with stimulants in pediatric visits: practice versus knowledge. J Atten Disord 7:217-226.

Blanchard DC, Blanchard RJ (1999) Cocaine potentiates defensive behaviors related to fear and anxiety. Neurosci Biobehav Rev 23:981-991.

Böer U, Noll C, Cierny I, Krause D, Hiemke C, Knepel W (2010) A common mechanism of action of the selective serotonin reuptake inhibitors citalopram and fluoxetine: reversal of chronic psychosocial stress-induced increase in CRE/CREB-directed gene transcription in transgenic reporter gene mice. Eur J Pharmacol 633:33-38.

Bolaños CA, Nestler EJ (2004) Neurotrophic mechanisms in drug addiction. Neuromolecular Med 5:69-83.

Bolaños CA, Glatt SJ, Jackson D (1998) Subsensitivity to dopaminergic drugs in periadolescent rats: a behavioral and neurochemical analysis. Brain Res Dev Brain Res 111:25-33.

Bolaños CA, Trksak GH, Cohen OS, Jackson D (2002) Differential serotonergic inhibition of in vitro striatal $\left[{ }^{3} \mathrm{H}\right]$ acetylcholine release in prenatally cocaine-exposed male and female rats. Prog Neuropsychopharmacol Biol Psychiatry 26:1339-1348.

Bolaños CA, Perrotti LI, Edwards S, Eisch AJ, Barrot M, Olson VG, Russell DS, Neve RL, Nestler EJ (2003a) Phospholipase C $\gamma$ in distinct regions of the ventral tegmental area differentially modulates mood-related behaviors. J Neurosci 23:7569-7576.

Bolaños CA, Barrot M, Berton O, Wallace-Black D, Nestler EJ (2003b) Methylphenidate treatment during pre- and periadolescence alters behavioral responses to emotional stimuli at adulthood. Biol Psychiatry 54:1317-1329.

Bolaños CA, Willey MD, Maffeo ML, Powers KD, Kinka DW, Grausam KB, Henderson RP (2008) Antidepressant treatment can normalize adult behavioral deficits induced by early-life exposure to methylphenidate. Biol Psychiatry 63:309-316.

Borycz J, Zapata A, Quiroz C, Volkow ND, Ferré S (2008) 5-HT 1B receptor-mediated serotoninergic modulation of methylphenidate- 
induced locomotor activation in rats. Neuropsychopharmacology 33: $619-626$.

Brenhouse HC, Napierata L, Kussmaul L, Leussis M, Andersen SL (2009) Juvenile methylphenidate exposure and factors that influence incentive processing. Dev Neurosci 31:95-106.

Carlezon WA Jr, Konradi C (2004) Understanding the neurobiological consequences of early exposure to psychotropic drugs: linking behavior with molecules. Neuropharmacology 47 [Suppl 1]:47-60.

Carlezon WA Jr, Boundy VA, Haile CN, Lane SB, Kalb RG, Neve RL, Nestler EJ (1997) Sensitization to morphine induced by viral-mediated gene transfer. Science 277:812-814.

Carlezon WA Jr, Thome J, Olson VG, Lane-Ladd SB, Brodkin ES, Hiroi N, Duman RS, Neve RL, Nestler EJ (1998) Regulation of cocaine reward by CREB. Science 282:2272-2275.

Carlezon WA Jr, Mague SD, Andersen SL (2003) Enduring behavioral effects of early exposure to methylphenidate in rats. Biol Psychiatry 54:1330-1337.

Carlezon WA Jr, Duman RS, Nestler EJ (2005) The many faces of CREB. Trends Neurosci 28:436-445.

Castle L, Aubert RE, Verbrugge RR, Khalid M, Epstein RS (2007) Trends in medication treatment for ADHD. J Atten Disord 10:335-342.

Covington HE 3rd, Kikusui T, Goodhue J, Nikulina EM, Hammer RP Jr, Miczek KA (2005) Brief social defeat stress: long lasting effects on cocaine taking during a binge and zif268 mRNA expression in the amygdala and prefrontal cortex. Neuropsychopharmacology 30:310-321.

Cryan JF, Markou A, Lucki I (2002) Assessing antidepressant activity in rodents: recent developments and future needs. Trends Pharmacol Sci 23:238-245.

Daviss WB (2008) A review of co-morbid depression in pediatric ADHD: etiology, phenomenology, and treatment. J Child Adolesc Psychopharmacol 18:565-571.

De Deurwaerdère P, Bonhomme N, Lucas G, Le Moal M, Spampinato U (1996) Serotonin enhances striatal dopamine outflow in vivo through dopamine uptake sites. J Neurochem 66:210-215.

Detke MJ, Lucki I (1996) Detection of serotonergic and noradrenergic antidepressants in the rat forced swimming test: the effects of water depth. Behav Brain Res 73:43-46.

Duman RS (2004) Role of neurotrophic factors in the etiology and treatment of mood disorders. Neuromolecular Med 5:11-25.

Eisch AJ, Bolaños CA, de Wit J, Simonak RD, Pudiak CM, Barrot M, Verhaagen J, Nestler EJ (2003) Brain-derived neurotrophic factor in the ventral midbrain-nucleus accumbens pathway: a role in depression. Biol Psychiatry 54:994-1005.

Fumagalli F, Molteni R, Calabrese F, Frasca A, Racagni G, Riva MA (2005) Chronic fluoxetine administration inhibits extracellular signal-regulated kinase 1/2 phosphorylation in rat brain. J Neurochem 93:1551-1560.

Halladay LR, Iñiguez SD, Furqan F, Previte MC, Chisum AM, Crawford CA (2009) Methylphenidate potentiates morphine-induced antinociception, hyperthermia, and locomotor activity in young adult rats. Pharmacol Biochem Behav 92:190-196.

Han DD, Gu HH (2006) Comparison of the monoamine transporters from human and mouse in their sensitivities to psychostimulant drugs. BMC Pharmacol 6:6.

Iñiguez SD, Warren BL, Neve RL, Nestler EJ, Russo SJ, Bolaños-Guzmán CA (2008) Insulin receptor substrate-2 in the ventral tegmental area regulates behavioral responses to cocaine. Behav Neurosci 122:1172-1177.

Iñiguez SD, Warren BL, Parise EM, Alcantara LF, Schuh B, Maffeo ML, Manojlovic Z, Bolaños-Guzmán CA (2009) Nicotine exposure during adolescence induces a depression-like state in adulthood. Neuropsychopharmacology 34:1609-1624.

Iñiguez SD, Warren BL, Bolaños-Guzmán CA (2010a) Short- and longterm functional consequences of fluoxetine exposure during adolescence in male rats. Biol Psychiatry 67:1057-1066.

Iñiguez SD, Vialou V, Warren BL, Cao JL, Alcantara LF, Davis LC, Manojlovic Z, Neve RL, Russo SJ, Han MH, Nestler EJ, Bolaños-Guzmán CA (2010b) Extracellular signal-regulated kinase- 2 within the ventral tegmental area regulates responses to stress. J Neurosci 30:7652-7663.

Iñiguez SD, Warren BL, Neve RL, Russo SJ, Nestler EJ, Bolaños-Guzmán CA (2010c) Viral-mediated expression of extracellular signal-regulated kinase-2 in the ventral tegmental area modulates behavioral responses to cocaine. Behav Brain Res 214:460-464.

Iñiguez SD, Charntikov S, Baella SA, Herbert MS, Bolaños-Guzmán CA,
Crawford CA (2011) Post-training cocaine exposure facilitates spatial memory consolidation in C57BL/6 mice. Hippocampus. Advance online publication. Retrieved June 14, 2011. doi:10.1002/hipo.20941.

Karpova NN, Lindholm J, Pruunsild P, Timmusk T, Castrén E (2009) Longlasting behavioural and molecular alterations induced by early postnatal fluoxetine exposure are restored by chronic fluoxetine treatment in adult mice. Eur Neuropsychopharmacol 19:97-108.

Krishnan V, Han MH, Graham DL, Berton O, Renthal W, Russo SJ, Laplant Q, Graham A, Lutter M, Lagace DC, Ghose S, Reister R, Tannous P, Green TA, Neve RL, Chakravarty S, Kumar A, Eisch AJ, Self DW, Lee FS, et al. (2007) Molecular adaptations underlying susceptibility and resistance to social defeat in brain reward regions. Cell 131:391-404.

Krishnan V, Han MH, Mazei-Robison M, Iñiguez SD, Ables JL, Vialou V, Berton O, Ghose S, Covington HE 3rd, Wiley MD, Henderson RP, Neve RL, Eisch AJ, Tamminga CA, Russo SJ, Bolaños CA, Nestler EJ (2008) AKT signaling within the ventral tegmental area regulates cellular and behavioral responses to stressful stimuli. Biol Psychiatry 64:691-700.

Lagace DC, Yee JK, Bolaños CA, Eisch AJ (2006) Juvenile administration of methylphenidate attenuates adult hippocampal neurogenesis. Biol Psychiatry 60:1121-1130.

LaPlant Q, Vialou V, Covington HE 3rd, Dumitriu D, Feng J, Warren BL, Maze I, Dietz DM, Watts EL, Iñiguez SD, Koo JW, Mouzon E, Renthal W, Hollis F, Wang H, Noonan MA, Ren Y, Eisch AJ, Bolaños CA, Kabbaj M, et al. (2010) Dnmt3a regulates emotional behavior and spine plasticity in the nucleus accumbens. Nat Neurosci 13:1137-1143.

Lee PS, Shaw LB, Choe LH, Mehra A, Hatzimanikatis V, Lee KH (2003) Insights into the relation between mRNA and protein expression patterns: II. Experimental observations in Escherichia coli. Biotechnol Bioeng 84:834-841.

Li N, Lee B, Liu RJ, Banasr M, Dwyer JM, Iwata M, Li XY, Aghajanian G, Duman RS (2010) mTOR-dependent synapse formation underlies the rapid antidepressant effects of NMDA antagonists. Science 329:959-964.

Lu L, Dempsey J, Liu SY, Bossert JM, Shaham Y (2004) A single infusion of brain-derived neurotrophic factor into the ventral tegmental area induces long-lasting potentiation of cocaine seeking after withdrawal. J Neurosci 24:1604-1611.

Lu L, Koya E, Zhai H, Hope BT, Shaham Y (2006) Role of ERK in cocaine addiction. Trends Neurosci 29:695-703.

Lucki I (1997) The forced swimming test as a model for core and component behavioral effects of antidepressant drugs. Behav Pharmacol 8:523-532.

Mague SD, Andersen SL, Carlezon WA Jr (2005) Early developmental exposure to methylphenidate reduces cocaine-induced potentiation of brain stimulation reward in rats. Biol Psychiatry 57:120-125.

McClung CA, Nestler EJ (2003) Regulation of gene expression and cocaine reward by CREB and DeltaFosB. Nat Neurosci 6:1208-1215.

Mehra A, Lee KH, Hatzimanikatis V (2003) Insights into the relation between mRNA and protein expression patterns: I. Theoretical considerations. Biotechnol Bioeng 84:822-833.

Montgomery KC, Monkman JA (1955) The relation between fear and exploratory behavior. J Comp Physiol Psychol 48:132-136.

Mutschler NH, Miczek KA, Hammer RP Jr (2000) Reduction of zif268 messenger RNA expression during prolonged withdrawal following "binge" cocaine self-administration in rats. Neuroscience 100:531-538.

Nestler EJ, Carlezon WA Jr (2006) The mesolimbic dopamine reward circuit in depression. Biol Psychiatry 59:1151-1159.

Neve RL, Howe JR, Hong S, Kalb RG (1997) Introduction of the glutamate receptor subunit 1 into motor neurons in vitro and in vivo using a recombinant herpes simplex virus. Neuroscience 79:435-447.

Olson VG, Zabetian CP, Bolaños CA, Edwards S, Barrot M, Eisch AJ, Hughes T, Self DW, Neve RL, Nestler EJ (2005) Regulation of drug reward by cAMP response element-binding protein: evidence for two functionally distinct subregions of the ventral tegmental area. J Neurosci 25:5553-5562.

Paxinos G, Watson C (1997) The rat brain in stereotaxic coordinates, Ed 3. San Diego: Academic.

Perrine SA, Sheikh IS, Nwaneshiudu CA, Schroeder JA, Unterwald EM (2008) Withdrawal from chronic administration of cocaine decreases delta opioid receptor signaling and increases anxiety- and depression-like behaviors in the rat. Neuropharmacology 54:355-364.

Porsolt RD, Le Pichon M, Jalfre M (1977) Depression: a new animal model sensitive to antidepressant treatments. Nature 266:730-732. 
Reed AL, Happe HK, Petty F, Bylund DB (2008) Juvenile rats in the forcedswim test model the human response to antidepressant treatment for pediatric depression. Psychopharmacology (Berl) 197:433-441.

Robinson MJ, Harkins PC, Zhang J, Baer R, Haycock JW, Cobb MH, Goldsmith EJ (1996) Mutation of position 52 in ERK2 creates a nonproductive binding mode for adenosine 5 '-triphosphate. Biochemistry 35 : 5641-5646.

Rushton JL, Whitmire JT (2001) Pediatric stimulant and selective serotonin reuptake inhibitor prescription trends: 1992 to 1998. Arch Pediatr Adolesc Med 155:560-565.

Russo SJ, Bolaños CA, Theobald DE, DeCarolis NA, Renthal W, Kumar A, Winstanley CA, Renthal NE, Wiley MD, Self DW, Russell DS, Neve RL, Eisch AJ, Nestler EJ (2007) IRS2-Akt pathway in midbrain dopamine neurons regulates behavioral and cellular responses to opiates. Nat Neurosci 10:93-99.

Safer DJ (2006) Should selective serotonin reuptake inhibitors be prescribed for children with major depressive and anxiety disorders? Pediatrics 118:1248-1251.

Safer DJ, Zito JM, DosReis S (2003) Concomitant psychotropic medication for youths. Am J Psychiatry 160:438-449.

Sekine Y, Suzuki K, Ramachandran PV, Blackburn TP, Ashby CR Jr (2007) Acute and repeated administration of fluoxetine, citalopram, and paroxetine significantly alters the activity of midbrain dopamine neurons in rats: an in vivo electrophysiological study. Synapse 61:72-77.

Spear LP (2000) The adolescent brain and age-related behavioral manifestations. Neurosci Biobehav Rev 24:417-463.

Spencer TJ (2006) ADHD and comorbidity in childhood. J Clin Psychiatry 67 [Suppl 8]:27-31.

Steiner H, Van Waes V, Marinelli M (2010) Fluoxetine potentiates methylphenidate-induced gene regulation in addiction-related brain regions: concerns for use of cognitive enhancers? Biol Psychiatry 67: 592-594.

Subramaniam S, Unsicker K (2010) ERK and cell death: ERK1/2 in neuronal death. FEBS J 277:22-29.

Thanos PK, Michaelides M, Benveniste H, Wang GJ, Volkow ND (2007) Effects of chronic oral methylphenidate on cocaine self-administration and striatal dopamine $\mathrm{D}_{2}$ receptors in rodents. Pharmacol Biochem Behav 87:426-433.

Turgeon SM, Pollack AE, Fink JS (1997) Enhanced CREB phosphorylation and changes in c-Fos and FRA expression in striatum accompany amphetamine sensitization. Brain Res 749:120-126.

Tzschentke TM (1998) Measuring reward with the conditioned place preference paradigm: a comprehensive review of drug effects, recent progress and new issues. Prog Neurobiol 56:613-672.

Van Waes V, Beverley J, Marinelli M, Steiner H (2010) Selective serotonin reuptake inhibitor antidepressants potentiate methylphenidate (Ritalin)- induced gene regulation in the adolescent striatum. Eur J Neurosci 32:435-447.

Vialou V, Robison AJ, Laplant QC, Covington HE 3rd, Dietz DM, Ohnishi YN, Mouzon E, Rush AJ 3rd, Watts EL, Wallace DL, Iñiguez SD, Ohnishi YH, Steiner MA, Warren BL, Krishnan V, Bolaños CA, Neve RL, Ghose S, Berton O, Tamminga CA, et al. (2010) DeltaFosB in brain reward circuits mediates resilience to stress and antidepressant responses. Nat Neurosci 13:745-752.

Volkow ND, Wang GJ, Fowler JS, Logan J, Franceschi D, Maynard L, Ding YS, Gatley SJ, Gifford A, Zhu W, Swanson JM (2002) Relationship between blockade of dopamine transporters by oral methylphenidate and the increases in extracellular dopamine: therapeutic implications. Synapse 43:181-187.

Wallace DL, Vialou V, Rios L, Carle-Florence TL, Chakravarty S, Kumar A, Graham DL, Green TA, Kirk A, Iñiguez SD, Perrotti LI, Barrot M, DiLeone RJ, Nestler EJ, Bolaños-Guzmán CA (2008) The influence of $\Delta$ FosB in the nucleus accumbens on natural reward-related behavior. J Neurosci 28:10272-10277.

Wallace DL, Han MH, Graham DL, Green TA, Vialou V, Iñiguez SD, Cao JL, Kirk A, Chakravarty S, Kumar A, Krishnan V, Neve RL, Cooper DC, Bolaños CA, Barrot M, McClung CA, Nestler EJ (2009) CREB regulation of nucleus accumbens excitability mediates social isolation-induced behavioral deficits. Nat Neurosci 12:200-209.

Wargin W, Patrick K, Kilts C, Gualtieri CT, Ellington K, Mueller RA, Kraemer G, Breese GR (1983) Pharmacokinetics of methylphenidate in man, rat and monkey. J Pharmacol Exp Ther 226:382-386.

Waxmonsky J (2003) Assessment and treatment of attention deficit hyperactivity disorder in children with comorbid psychiatric illness. Curr Opin Pediatr 15:476-482.

Wiley MD, Poveromo LB, Antapasis J, Herrera CM, Bolaños Guzmán CA (2009) Kappa-opioid system regulates the long-lasting behavioral adaptations induced by early-life exposure to methylphenidate. Neuropsychopharmacology 34:1339-1350.

Willner P, Towell A, Sampson D, Sophokleous S, Muscat R (1987) Reduction of sucrose preference by chronic unpredictable mild stress, and its restoration by a tricyclic antidepressant. Psychopharmacology (Berl) 93:358-364.

Yang PB, Swann AC, Dafny N (2006) Chronic methylphenidate modulates locomotor activity and sensory evoked responses in the VTA and NAc of freely behaving rats. Neuropharmacology 51:546-556.

Yano M, Steiner H (2007) Methylphenidate and cocaine: the same effects on gene regulation? Trends Pharmacol Sci 28:588-596.

Zito JM, Derivan AT, Kratochvil CJ, Safer DJ, Fegert JM, Greenhill LL (2008) Off-label psychopharmacologic prescribing for children: history supports close clinical monitoring. Child Adolesc Psychiatry Ment Health 2:24 